Article

\title{
Operation and Power Flow Control of Multi-Terminal DC Networks for Grid Integration of Offshore Wind Farms Using Genetic Algorithms
}

\author{
Rodrigo Teixeira Pinto ${ }^{1, *}$, Sílvio Fragoso Rodrigues ${ }^{1}$, Edwin Wiggelinkhuizen ${ }^{2}$, \\ Ricardo Scherrer ${ }^{3}$, Pavol Bauer ${ }^{1}$ and Jan Pierik ${ }^{2}$ \\ ${ }^{1}$ Electrical Power Processing Group, Technical University of Delft, Mekelweg 4, Delft 2628 CD, \\ The Netherlands; E-Mails: s.m.fragosorodrigues@tudelft.nl (S.F.R.); p.bauer@tudelft.nl (P.B.) \\ ${ }^{2}$ Wind Energy Group, Energy Research Centre of the Netherlands (ECN), Westerduinweg 3, \\ Petten 1755 LE, The Netherlands; E-Mails: wiggelinkhuizen@ecn.nl (E.W.); pierik@ecn.nl (J.P.) \\ ${ }^{3}$ Bids, Proposals \& Sales Operations, Alcatel-Lucent, Av. Marginal Direita da Anchieta 400, \\ São Paulo 04182-901, Brazil; E-Mail: ricardo_cordeiro.scherrer@ alcatel-lucent.com \\ * Author to whom correspondence should be addressed; E-Mail: R.TeixeiraPinto@ tudelft.nl; \\ Tel.: +31-15-278-5744; Fax: +31-15-278-2968.
}

Received: 11 October 2012; in revised form: 24 November 2012 / Accepted: 14 December 2012 / Published: 24 December 2012

\begin{abstract}
For achieving the European renewable electricity targets, a significant contribution is foreseen to come from offshore wind energy. Considering the large scale of the future planned offshore wind farms and the increasing distances to shore, grid integration through a transnational DC network is desirable for several reasons. This article investigates a nine-node DC grid connecting three northern European countries-namely UK, The Netherlands and Germany. The power-flow control inside the multi-terminal DC grid based on voltage-source converters is achieved through a novel method, called distributed voltage control (DVC). In this method, an optimal power flow (OPF) is solved in order to minimize the transmission losses in the network. The main contribution of the paper is the utilization of a genetic algorithm (GA) to solve the OPF problem while maintaining an N-1 security constraint. After describing main DC network component models, several case studies illustrate the dynamic behavior of the proposed control method.
\end{abstract}

Keywords: HVDC transmission; voltage-source converters; power electronics; DC networks; offshore wind energy; control theory; optimal power flow; genetic algorithms 


\section{Introduction}

Nowadays, due to sociopolitical and economical reasons, there is an increasing demand for electricity generated via renewable energy sources. However, the energy per unit area yield of these sources is usually low [1]. As space to install new renewable projects on land becomes scarce, offshore wind farms will constitute an advantageous alternative in terms of area, cost effectiveness, and yearly yielded energy [2]. With over $100 \mathrm{GW}$ of offshore wind energy projects in development or planning stage, the European offshore potential is expected to account for $16 \%$ of all renewable electricity produced in the continent by 2030 [3-5].

As the power rating of modern wind turbines continues to evolve, with $7.5 \mathrm{MW}$ units already available and $10 \mathrm{MW}$ ones under development [6], it is expected that offshore wind farms will also have increasing installed capacity in the near future. In fact, the London Array I offshore wind farm, to be commissioned on April 2013, will have 630 MW installed capacity [7].

Different European studies recognize a transnational offshore grid infrastructure as the most efficient way to integrate large amounts of offshore wind power into the national electricity networks $[5,8]$. Moreover, these transnational grids could boost the electricity market between countries [9]. Since new offshore projects tend to be erected increasingly further from shore and with growing installed capacity, probably the transnational grid will use DC transmission technology. For large and distant offshore wind farms, the use of HVDC technology is the most efficient and economical way of transmitting the produced energy to shore [2].

However, before a Multi-Terminal DC (MTDC) network — such as the North Sea Transnational gridcan go from planning to reality, several economic, regulatory and technical issues must be addressed [10]. The most important technical aspects are the choice of HVDC converter topology [11-14], the necessity of dc/dc converters [15,16], the need for protection schemes [17-19], dynamic stability issues [20-22], and power-flow control strategies [23-26].

The present article aims at demonstrating how a novel control strategy — the distributed voltage control (DVC) — can be employed, together with a genetic algorithm optimization, to operate large MTDC networks with any desired optimal power flow [27]. The paper is organized as follows. Firstly, the model of the proposed MTDC network is explained, together with its main components such as the wind farms and VSC-HVDC terminals. Secondly, the distributed voltage control method is introduced and a thorough explanation is given on how it operates. Next, four different case studies encompassing several operating points of the MTDC network are analyzed through detailed numerical dynamic simulations. Lastly, the results of the analyzed case studies are discussed and conclusions are drawn.

\section{Model Description}

To study the control of a multi-terminal dc grid—such as the North Sea Transnational grid-a simplified topology, containing nine nodes has been chosen. This topology represents only a fraction of the possible future grid and is located in the southern part of the North Sea. It comprises connection points to three different countries, i.e., the United Kingdom $(U K)$, The Netherlands $(N L)$ and Germany $(D E)$, as shown in Figure 1. 
Figure 1. Topology of the modeled MTDC grid.

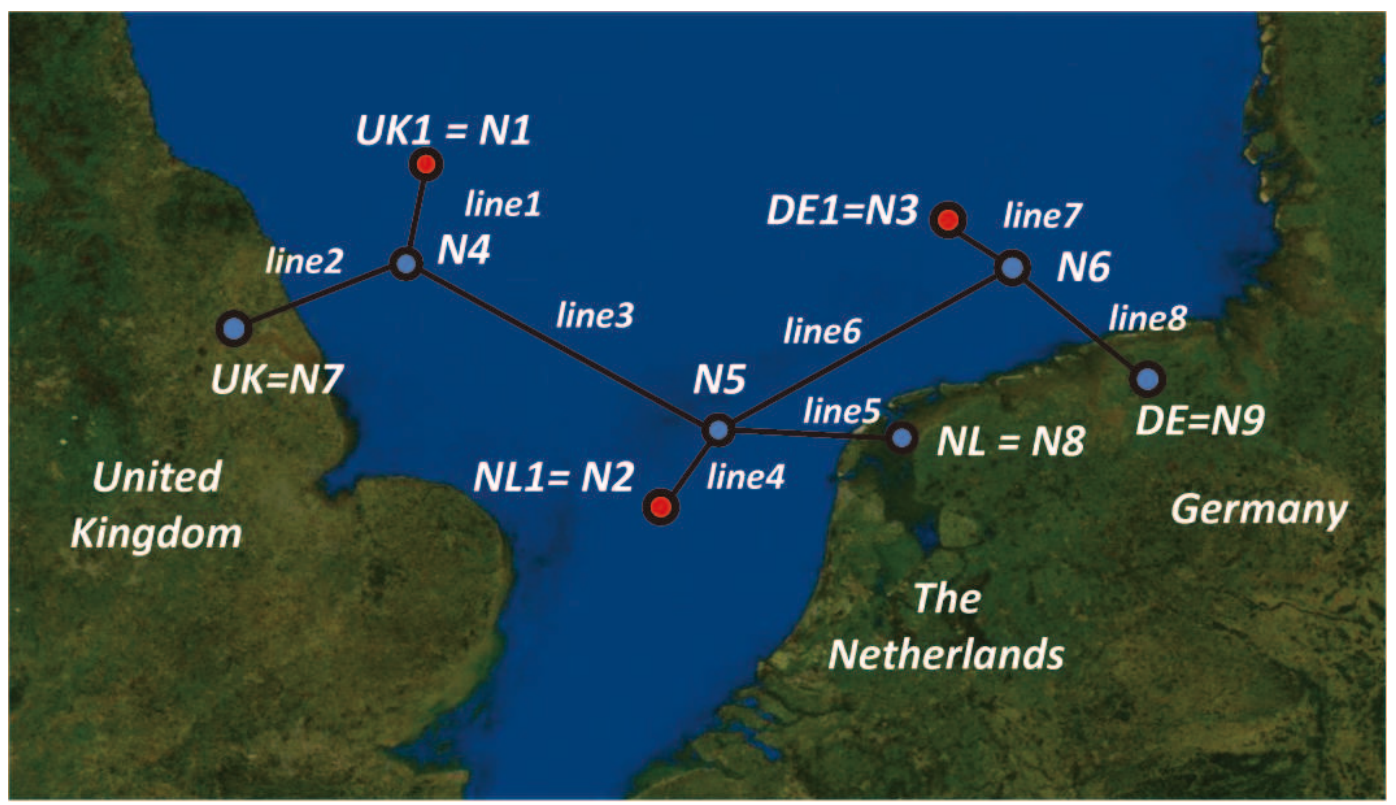

Each country has its own offshore wind farm (the red dots in Figure 1) named UK1, NL1 and DE1. The black lines represent a pair of HVDC transmission cables and the intermediate nodes- N4, N5 and N6-are cable T-joints. The wind farms size and location are derived by clustering the main offshore wind farms in the North Sea southern part; it includes wind farms in construction and planning phase.

The nominal power of each wind farm is $1 \mathrm{GW}$ (see Figure 2). The wind farms, as well as the ac networks, are connected to the MTDC grid through a single voltage-source converter (VSC) station. The ratings of all six VSC stations are chosen equal to $1 \mathrm{GW}$ to make it possible to transport all wind power to the country that owns the wind farm. Trading offshore wind or onshore generated power is possible via line 3 and line6, as shown in Figure 1, up to the VSC stations capacity. Table 1 gives the dc transmission length of each cable whereas other MTDC system parameters are given in Table 2.

Figure 2. Components of the modeled MTDC grid (DE nodes).

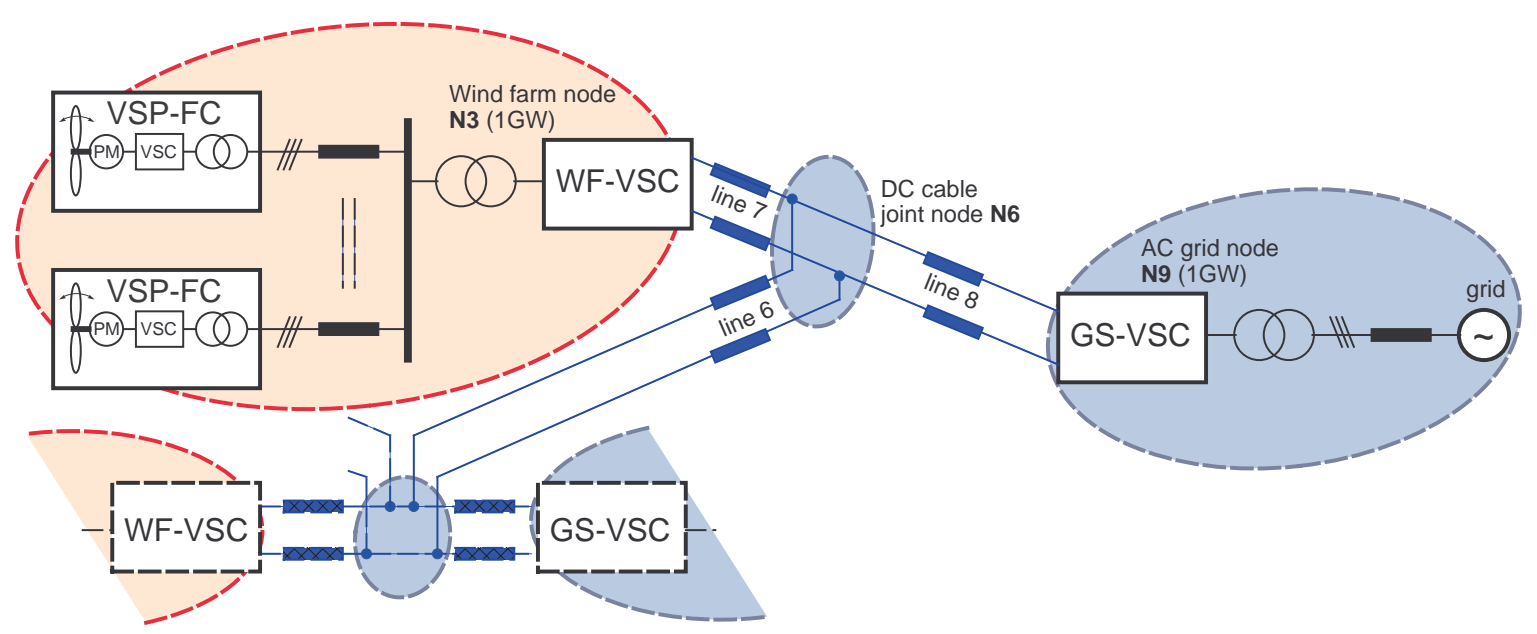


Table 1. MTDC network lines.

\begin{tabular}{lcc|lcc}
\hline Line Name & Nodes & Length $[\mathbf{k m}]$ & Line Name & Nodes & Length $[\mathbf{k m}]$ \\
\hline line1 & N1-N4 & 60 & line5 & N5-N8 & 120 \\
line2 & N4-N7 & 120 & line6 & N5-N6 & 220 \\
line3 & N4-N5 & 190 & line7 & N3-N6 & 50 \\
line4 & N2-N5 & 60 & line8 & N6-N9 & 110 \\
\hline
\end{tabular}

Table 2. MTDC network parameters.

\begin{tabular}{lccc}
\hline Parameter & Symbol & Unit & Value \\
\hline System Base Power & $S_{b}$ & $\mathrm{MVA}$ & 1000 \\
\hline AC Grid Short-Circuit Power & $S_{k}$ & $\mathrm{MVA}$ & 3000 \\
AC Grid Voltage-HV Side & $E_{h}$ & $\mathrm{kV}$ & 380 \\
AC Grid Voltage-LV Side & $E_{l}$ & $\mathrm{kV}$ & 275 \\
\hline OWF Collection Voltage & $V_{o w f}$ & $\mathrm{kV}$ & 33 \\
OWF-VSC Voltage & $V_{c}$ & $\mathrm{kV}$ & 275 \\
\hline Traformers Impedance & $Z_{t r}$ & $\mathrm{pu}$ & $0.005+j 0.100$ \\
VSC Filter Size-AC Grid & $r_{a c}$ & $\mathrm{MVA}$ & 200 \\
VSC Filter Size-OWF & $r_{o w f}$ & $\mathrm{MVA}$ & 50 \\
Phase reactor Impedance & $Z_{p}$ & $\mathrm{pu}$ & $0.003+j 0.150$ \\
VSC DC-side Capacitor & $C$ & $\mu \mathrm{F}$ & 75 \\
\hline MTDC Network Voltage & $V_{d c}$ & $\mathrm{kV}$ & \pm 320 \\
DC Cable Resistance & $R_{d c}$ & $\Omega / \mathrm{km}$ & 0.0195 \\
DC Cable Inductance & $L_{d c}$ & $\mathrm{mH} / \mathrm{km}$ & 19 \\
DC Cable Capacitance & $C_{d c}$ & $\mathrm{nF} / \mathrm{km}$ & 220 \\
DC Cable Cross Section & $A_{d c}$ & $\mathrm{~mm}{ }^{2}$ & 2200 \\
DC Cable Rated Current & $I_{d c}$ & $\mathrm{kA}$ & 2.086 \\
\hline
\end{tabular}

\subsection{AC Network Model}

The ac grids are modeled as an infinite bus behind a short-circuit series impedance. The exception is the UK ac grid, which is modeled as a single synchronous generator with a series line impedance and a shunt resistance to model a 3-phase fault. These ac grids do not have other loads or generation units connected to them. Their short-circuit power is chosen equal to $3 \mathrm{GW}$, as shown in Table 2.

\subsection{Wind Farm Model}

The wind farms power output should be as realistic as possible. Therefore, the wind turbine outputs have been combined for different average wind speeds and time delays, as illustrated in Figure 3, to obtain the spatial smoothening effect.

Figure 3 shows the wind farm layout, with the undisturbed wind speed $V_{w}(t)$ and average speed $\bar{V}_{w 1}$. The rotor wakes decrease the average wind speed row after row, while the wind direction is kept uniform. 
The applied delay times are inversely related to the average wind speed, which results in sufficiently low correlation between the time series [28].

Figure 3. Synthesized wind farm output power.

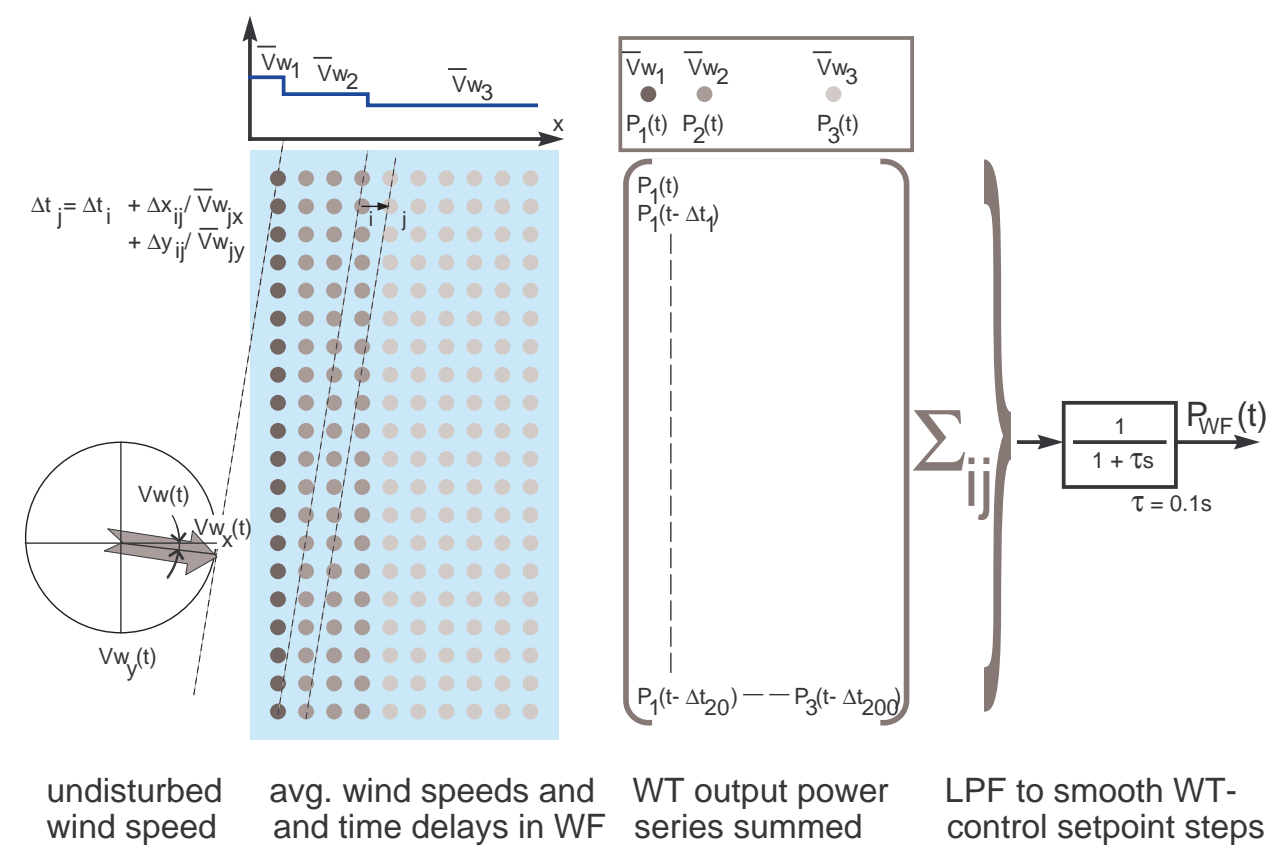

The wind farm models aggregate a limited number of wind turbines to match the nominal power of the wind farm. The turbines are 5-MW PMSG with full converter. The collection grid is represented by a lumped model with a single cable and the farm is connected to the MTDC grid through a single converter (WF-VSC).

\subsection{Wind Turbine Model}

The turbine model is based on the wind turbine mechanical power generated from a given wind speed $\left(V_{w}\right)$. The available mechanical power $\left(P_{m}\right)$ is defined as the power contained in the wind passing through the rotor area $\left(A_{r}\right)$ multiplied by the power coefficient $\left(C_{p}(\lambda, \beta)\right)$ [29].

Although DFIG turbines still constitutes the most used and marketed wind turbine type, PSMG turbines offer a higher range of dynamic speed control, hence, the latter will likely be employed in offshore wind farms. The PMSG control strategy used is field oriented control, where the permanent-magnet flux is aligned with the rotating frame d-axis so the q-axis machine flux is zero, $\bar{\lambda}_{m}=0$ [30].

The turbine speed is variable and controlled to always yield the maximum efficiency. The current controller is important to guarantee the rotor flux is aligned with the d-axis of the rotating reference frame by imposing $i_{d}^{*}=0$, while the q-axis current reference $\left(i_{q}^{*}\right)$ will come from the speed controller. The speed controller model is based on the generator shaft dynamics and on the fact the q-axis current will control the electric torque. Below rated wind speed, the rotor speed set-point is set to optimum $\lambda$ by controlling the generator torque. Additionally, above rated wind, the aerodynamic power is also controlled by changing the blade pitch angle. More details about the controller can be found in [31]. 


\subsection{VSC-HVDC Model}

Although the classic LCC-HVDC transmission technology is still preferred for long bulk power transmission [32], the smaller footprint and more flexible characteristics of VSC-HVDC systems make them the most convenient choice for the connection of offshore wind farms [2,5,9]. The VSC-HVDC model used is an averaged lossless model [33]. A more detailed switching model of the converter may be of interest when commutation losses, switching harmonics or ripple in the converter currents and voltages need to be taken into consideration. In the averaged model, the closed-loop bandwidth of the VSC current controller is usually kept at least 5 times lower than the converter switching frequency. In this way, the converter switching behavior can be neglected when evaluating the dynamic response of the MTDC network as a whole. The employed VSC model is modular and contains several modules [34]. Its single-line representation and the signal flow are shown in Figure 4.

Figure 4. (a) Single-line diagram of the VSC-HVDC model; (b) Signal flow inside the model.

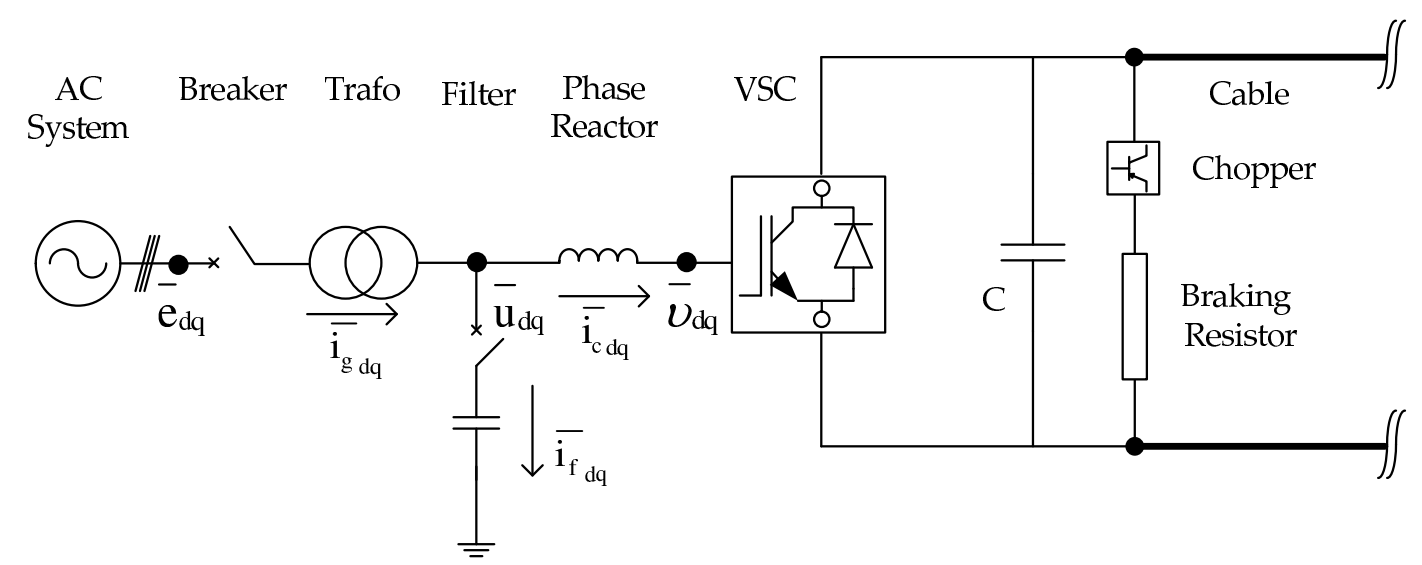

(a)

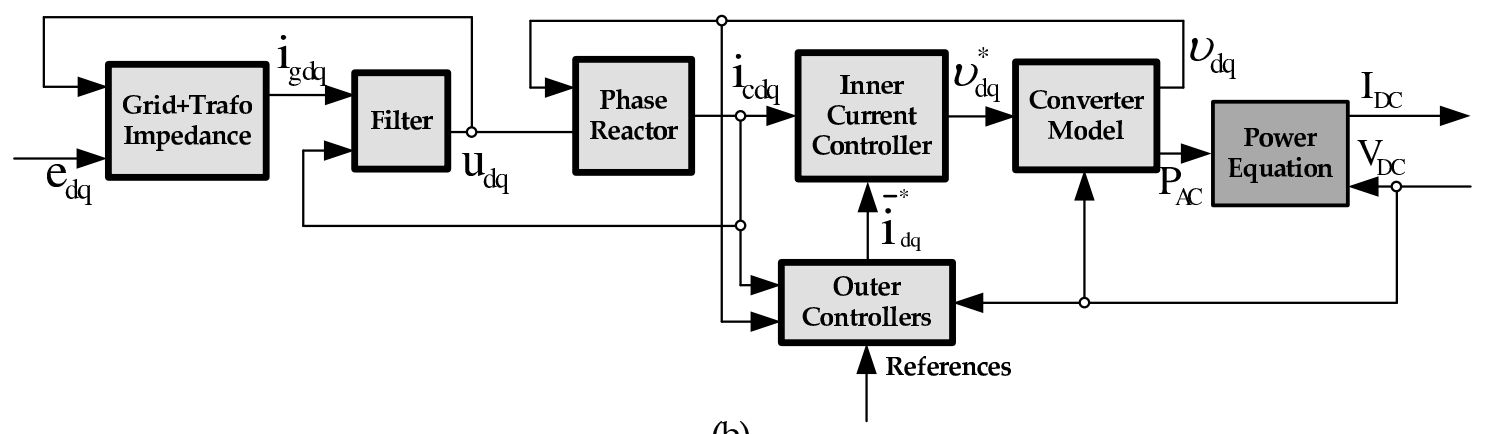

(b)

\subsubsection{Grid-Side VSC Control}

In a VSC-HVDC system, the active power and the reactive power can be controlled independently. The outer controllers are responsible for providing the current reference signals for the inner current controller (Figure 4). In all the outer controllers, PI regulators are employed to annul steady-state errors (Figure 5).

The grid-side VSC terminals are set to control the reactive power exchanged with the AC network. Nowadays, especially in countries where the wind power penetration is rapidly increasing, large wind 
farms are required to actively participate in the power system control just as conventional power plants $[35,36]$. Depending on the grid code, the specifications for reactive power control might be given as a voltage range, a reactive power range or a power factor (PF) range at the PCC [37].

Figure 5. Grid-side VSC-HVDC control diagram with outer controllers.

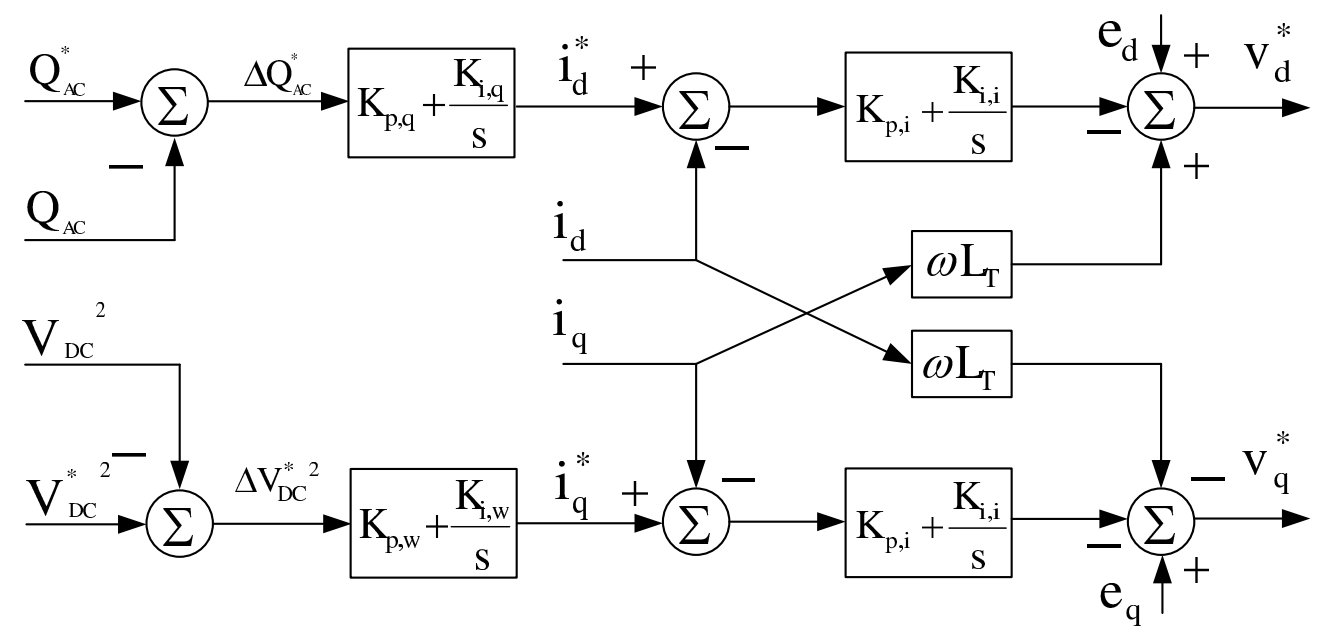

Additionally, all the GS-VSC terminals are set to control the MTDC network voltage at their respective node. The direct-voltage outer controller operates on the square of the direct voltage to avoid nonlinearities. The power flow inside the MTDC network is controlled by changing the direct-voltage references of the GS-VSC terminals.

The GS-VSC control diagram is shown in Figure 5. The reactive power reference, $Q_{A C}^{*}$, is set to comply with the national grid code where the GS-VSC is connected. On the other hand, the direct voltage reference, $V_{D C}^{*}{ }^{2}$, is obtained from the distributed voltage control (DVC) algorithm, which is explained in Section 3.

\subsubsection{Wind-Farm VSC Control}

The WF-VSC controls the collector bus voltage and frequency in the wind farm grid to fixed values. The individual WT-VSCs maximize the produced active power, sometimes also producing a small amount of reactive power in order to level the voltage profile in the collection grid.

\subsection{Network Model}

The MTDC network model represents each DC cable by a PI section. Half of the cable capacitance is added to the VSC capacitance at every VSC terminal. The nominal voltage is assumed to be balanced between the two poles. The MTDC model is derived through a state-space matrix representation. Figure 6 shows a generic representation of a MTDC network for offshore wind energy integration.

Applying Kirchhoff laws to the network in Figure $6-j$ nodes and $i$ lines-yields:

$$
\left\{\begin{array}{l}
I_{L i}=\frac{V_{D C i}-V_{D C j}}{R_{i}+s L_{i}} \Leftrightarrow s I_{L i}=\frac{V_{D C i}}{L_{i}}-\frac{V_{D C j}}{L_{i}}-I_{L i} \frac{R_{i}}{L_{i}} \\
s V_{D C j}=\frac{1}{C_{j}}\left(I_{D C j}-\sum_{i=1}^{L} I_{M i j} \cdot I_{L i}\right)
\end{array}\right.
$$


where $I_{L i}$ is the current flowing through line $i ; R_{i}$ and $L_{i}$ are line $i$ series parameters, $V_{D C i}$ and $V_{D C j}$ are respectively the nodes $i$ and $j$ voltages, $C_{j}$ is the sum of node $j$ capacitances, and $I_{M i j}$ is MTDC network incidence matrix $i j$-th position.

Figure 6. Generic representation of a MTDC grid.

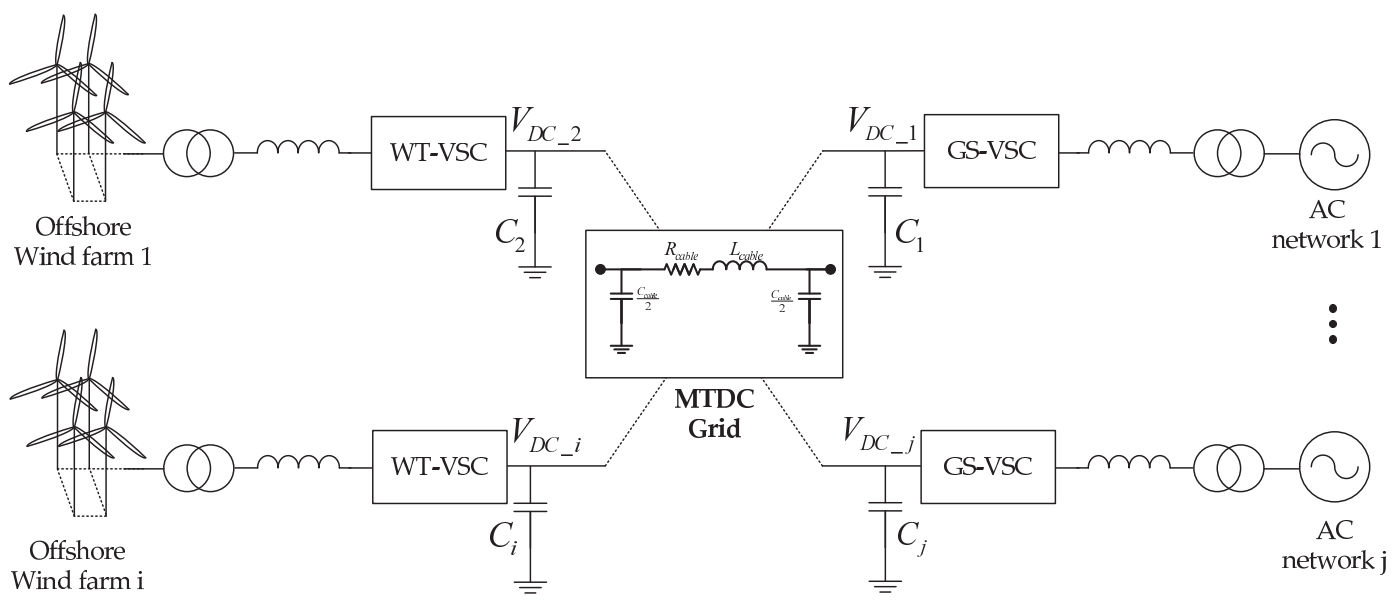

The state-space matrix representation of the MTDC system is then:

$$
\left\{\begin{array}{l}
\dot{\mathrm{x}}=\mathrm{Ax}+\mathrm{Bu} \\
\mathrm{y}=\mathrm{Cx}+\mathrm{Du}
\end{array}\right.
$$

The state vector, $\mathbf{x}$, in Equation (2), contains one equation per each energy-storage elementscapacitors and inductances_-inside the MTDC system. Thus, the state-variable vector is given by:

$$
\mathbf{x}=\left[\begin{array}{llllll}
V_{D C 1} & \ldots & V_{D C_{N}} & I_{L 1} & \ldots & I_{L_{L}}
\end{array}\right]^{T}{ }_{1 \times(N+L)}
$$

where $N$ and $L$ are, respectively, the total number of nodes and dc lines in the MTDC network.

The input vector, $\mathbf{u}$, is given by the net direct current injected at the VSC terminals:

$$
\mathbf{u}=\left[\begin{array}{lll}
I_{D C 1} & \ldots & I_{D C_{N}}
\end{array}\right]_{1 \times N}^{T}
$$

where $I_{D C j}$ is obtained as $P_{D C j} / V_{D C j}$.

Independently of the MTDC grid connections, all the state-space model matrices, displayed in Equation (2), can be obtained by using Equations (5-8). The information on how the lines inside the MTDC network are actually connected is obtained from the incidence matrix $\mathbf{I}_{\mathbf{M} L \times N}$.

The state matrix, $\mathbf{A}$, is composed out of 4 matrices:

$$
\mathbf{A}=\left[\begin{array}{ll}
\mathbf{A}^{11}{ }_{N \times N} & \mathbf{A}^{\mathbf{1 2}}{ }_{N \times L} \\
\mathbf{A}^{\mathbf{2 1}}{ }_{L \times N} & \mathbf{A}^{\mathbf{2 2}}{ }_{L \times L}
\end{array}\right]_{(N+L) \times(N+L)}
$$


The sub-matrices of $\mathbf{A}$ are given as:

$$
\begin{aligned}
\mathbf{A}^{\mathbf{1 1}}= & \mathbf{A} \mathbf{A}^{\mathbf{1 2}}=-\left[\mathbf{I}_{\mathbf{M}} \cdot\left[\begin{array}{cccc}
\frac{1}{C_{1}} & 0 & \cdots & 0 \\
0 & \frac{1}{C_{2}} & \ddots & \vdots \\
\vdots & \ddots & \ddots & 0 \\
0 & \cdots & 0 & \frac{1}{C_{N}}
\end{array}\right]\right) \\
\mathbf{A}^{\mathbf{2 1}}= & {\left[\begin{array}{cccc}
\frac{1}{L_{1}} & 0 & \cdots & 0 \\
0 & \frac{1}{L_{2}} & \ddots & \vdots \\
\vdots & \ddots & \ddots & 0 \\
0 & \cdots & 0 & \frac{1}{L_{L}}
\end{array}\right] \cdot \mathbf{I}_{\mathbf{M}} } \\
\mathbf{A}^{\mathbf{2 2}}= & {\left[\begin{array}{cccc}
-\frac{R_{1}}{L_{1}} & 0 & \cdots & 0 \\
0 & -\frac{R_{2}}{L_{2}} & \ddots & \vdots \\
\vdots & \ddots & \ddots & 0 \\
0 & \cdots & 0 & -\frac{R_{L}}{L_{L}}
\end{array}\right] }
\end{aligned}
$$

On the other hand, the input matrix, $\mathbf{B}$, is constituted of only 2 sub-matrices:

$$
\begin{aligned}
& \mathbf{B}=\left[\begin{array}{l}
\mathbf{B}^{11}{ }_{N \times N} \\
\mathbf{B}^{\mathbf{2 1}}{ }_{L \times N}
\end{array}\right]_{(N+L) \times N} \\
& \mathbf{B}^{\mathbf{1 1}}=\left[\begin{array}{cccc}
\frac{1}{C_{1}} & 0 & \cdots & 0 \\
0 & \frac{1}{C_{2}} & \ddots & \vdots \\
\vdots & \ddots & \ddots & 0 \\
0 & \cdots & 0 & \frac{1}{C_{N}}
\end{array}\right] \\
& \mathbf{B}^{\mathbf{2 1}}=\mathbf{0}
\end{aligned}
$$

The output matrix $\mathbf{C}$ and the feed-forward matrix $\mathbf{D}$ can be selected to obtain the desired output vector $\mathbf{y}$. Here, the output vector coincides with the state vector, therefore:

$$
\left\{\begin{array}{l}
\mathbf{C}=\mathbf{I}_{(N+L) \times(N \times L)} \\
\mathbf{D}=\mathbf{0}_{(N+L) \times N}
\end{array}\right.
$$

\section{MTDC Control Description}

Controlling the direct voltage inside a MTDC transmission system is equivalent to controlling the frequency in ac networks. A well-controlled direct voltage on a HVDC transmission network means the power is balanced amongst all nodes [38]. Usually, the control of point-to-point HVDC transmission systems is arranged as follows: one terminal controls the dc network voltage, whereas the other operates in current or power regulation mode. This control philosophy-of having only one converter controlling the direct voltage — can also be extended to MTDC networks, as in the voltage margin method $[25,39,40]$. 
However, as the MTDC network grows in size and complexity, having only one terminal responsible for voltage regulation makes it increasingly difficult to guarantee the power balance in the network. Hence, for large MTDC networks, it is not recommended to control the direct voltage at a sole terminal.

\subsection{The Distributed Voltage Control Method}

A more suitable control strategy is to have several terminals responsible for controlling the direct voltage inside the MTDC network. This increases reliability by adding redundancy and provides the possibility to control the dc power flow.

The distributed voltage control (DVC) method assigns each dc-voltage-controlling VSC terminal with a specific voltage set-point [27]. In this way, the MTDC network voltage control is distributed amongst several nodes and any feasible load-flow scenario can be accomplished. In addition, no single converter assumes alone the responsibility of balancing the power inside the transmission system. Figure 7 illustrates how the DVC method works.

Figure 7. Flow chart of the distributed voltage control method.

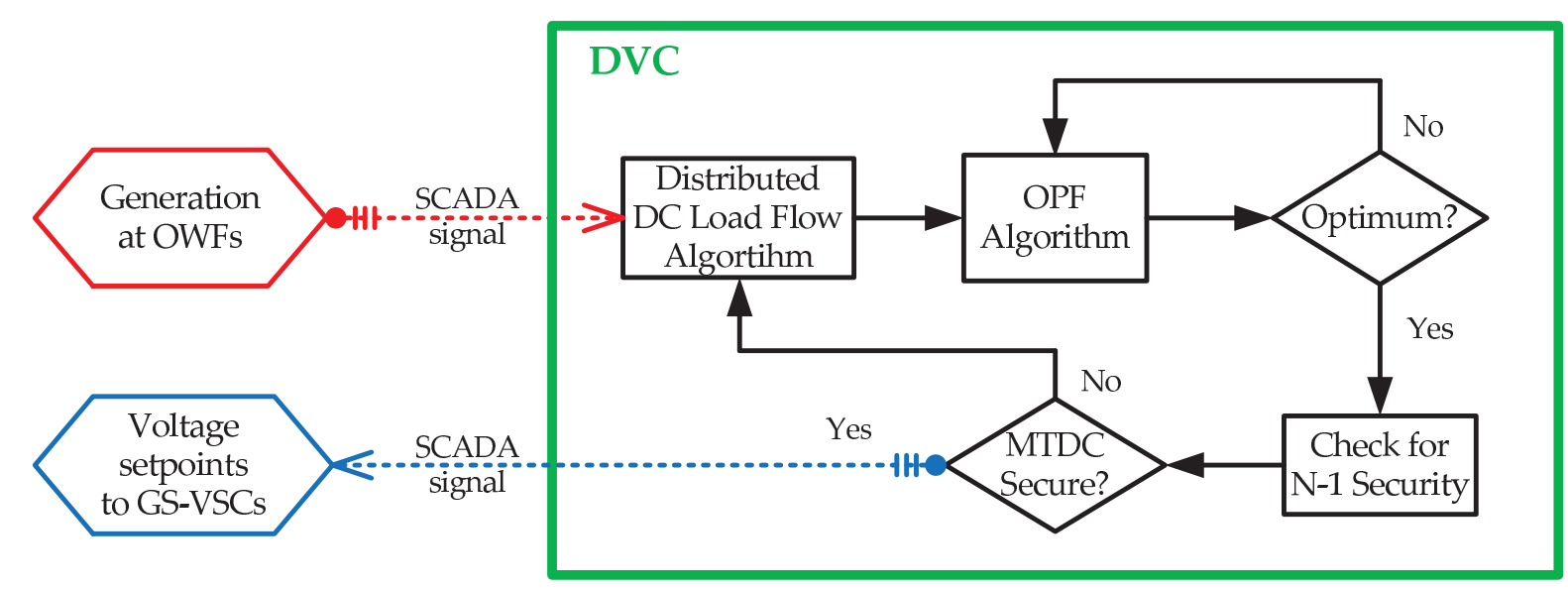

At first, the distributed voltage controller receives the power production at the OWFs. Then, a distributed dc load flow algorithm is run to obtain a first solution for the OPF algorithm. The OPF problem can be solved via any optimization method, such as a steepest gradient method or a genetic algorithm [27,41]. The constraints and specific parameters for the OPF algorithm are set by an independent system operator (ISO) [42]. Next, the OPF solution is checked for $N-1$ security. On that point, the GS-VSCs are made slack nodes, i.e., they control the direct voltage at their respective nodes to the value defined by the OPF algorithm. The distributed DC load-flow algorithm then runs $N$ load-flow scenarios, with one dc node defective at a time, to check whether the MTDC network is $N-1$ secure for the obtained power-flow scenario. In the end, the DVC sends the direct voltage set-points to the GS-VSCs.

The DVC method does not need a fast communication link between the network terminals. As it relies only on a central optimal power flow solution, SCADA communication systems can be used to gather the necessary information just as for power plant control in ac networks. The advantage of the DVC strategy is that, in practice, a desired load-flow scenario can be kept fixed for a certain amount of time (e.g., 15 min control cycle). Hence, in essence, a fast communication link with the ISO is also not 
needed. Nevertheless, it is necessary to be able to send the voltage references to the onshore GS-VSC stations once every control cycle.

In the DVC method, the dc system voltage references are obtained by means of a dc optimal power flow. The genetic algorithm that solves the OPF problem is briefly explained next.

\subsection{Genetic Algorithm}

Genetic algorithms (GAs) are one of the branches of evolutionary algorithms (EAs), first introduced by Holland in 1975 [43]. These algorithms are efficient and robust search and optimization tools that allow parallel search since a population of solutions is used. Each individual contained in the population is also designated as a chromosome. Moreover, such algorithms are highly flexible since, differently from most search methods, they do not require any information other than the evaluations of functions [44]. The function to be optimized is usually designated as fitness function.

In [27] a steepest descent gradient method was used to solve the optimal power flow (OPF) problem. Here, the main contribution is the utilization of a genetic algorithm (GA) to solve the OPF problem. The main points for using a GA are:

- no need for calculating derivatives;

- no information about the optimization goals is required besides evaluating the fitness function;

- it is possible to use continuous and discrete variables;

- it is easier to include problem constraints and variables boundaries;

- multi-objective optimization, even though not considered here, is possible.

In Figure 8 the flowchart of the genetic algorithm is depicted. Each step of the flowchart will be presented and explained next.

Step 1-Population initialization

At the initialization, a random population is created. The composition of each individual chromosome is given in Equation (9). Encoded in the chromosomes are the direct voltage references of all onshore nodes, the values for the augmented fitness function and the maximum constraint violation. All the variables are constrained by the values in Table 3.

$$
\mathbf{X}=\left[\begin{array}{lllll}
V_{D C 1}^{*} & \cdots & V_{D C n}^{*} & A u g_{F i t} & \text { Max } \\
\text { Const }
\end{array}\right]
$$

where $V_{D C j}^{*}$ is the dc system voltage reference of the $\mathrm{j}$-th onshore VSC, $A u g_{F i t}$ corresponds to the chromosome augmented fitness value and $\operatorname{Max}_{\text {Const }}$ stands for the value of the highest constraint violation. The genetic algorithm output is the direct voltage references of the GS-VSC nodes onshore, which is contained in $\mathbf{X}$. 
Figure 8. Flowchart of the Genetic Algorithm implemented to solve the load flow of the MTDC grid.

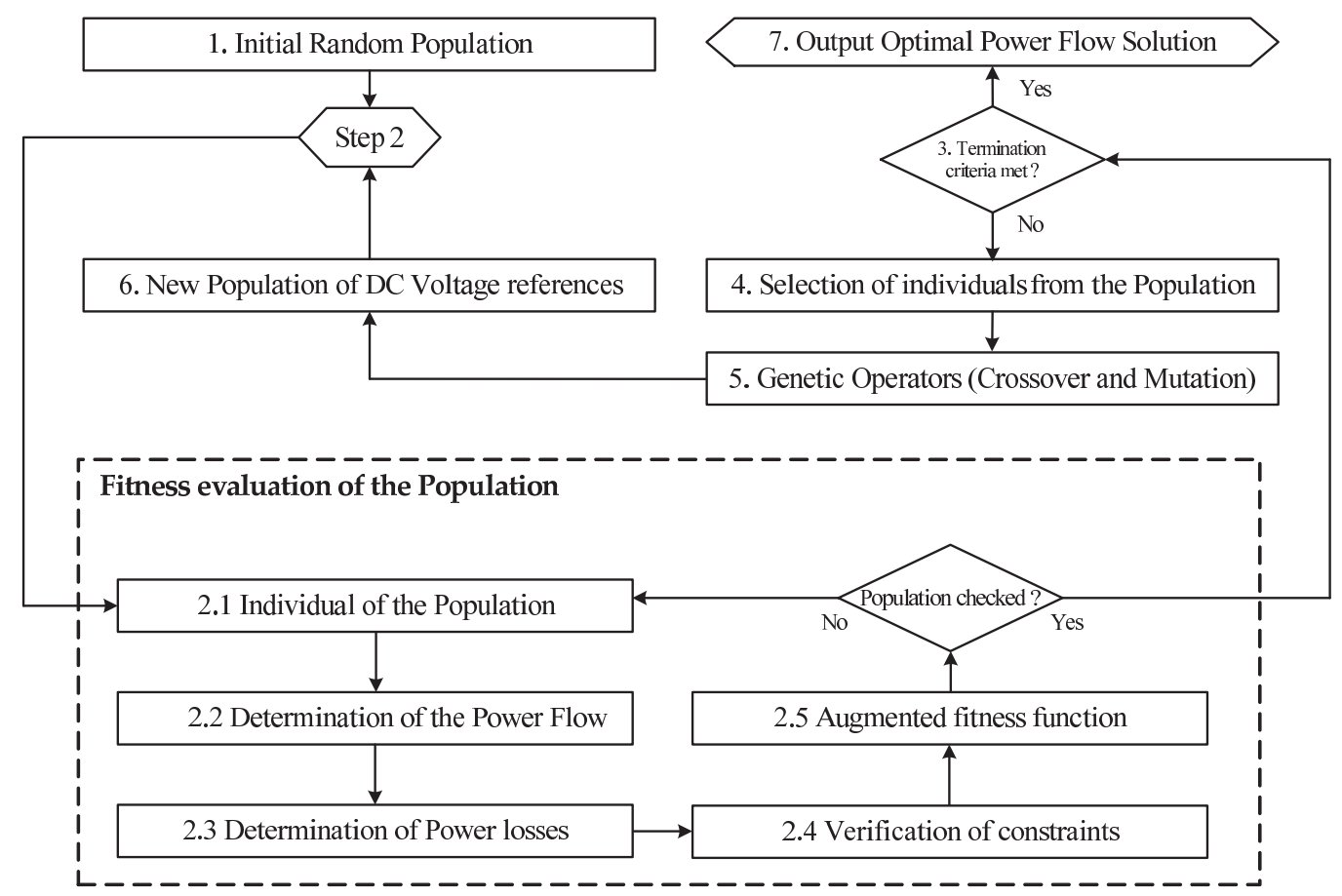

Table 3. Genetic Algorithm parameters.

\begin{tabular}{lc|lc}
\hline Parameter & Description & Parameter & Description \\
\hline Population size & 150 & Mutation & $10 \%$ \\
Tournament Selection & $4-$ th & Constraint violation & $10^{-5}$ \\
Mating Pool size & $9 \%$ & Upper boundary & $1.1 \mathrm{pu}$ \\
Crossover & $80 \%$ & Lower boundary & $0.9 \mathrm{pu}$ \\
Elite size & $1 \%$ & & \\
\hline
\end{tabular}

Step 2-Fitness evaluation

In Step 2, the objective function, i.e., fitness value, is evaluated for each chromosome. The objective function is the MTDC network losses, $P_{\text {loss }}$, calculated as:

$$
P_{\text {loss }}(\mathbf{X})=\mathbf{I}^{\mathbf{T}} \mathbf{R I}=\left(\mathbf{I}_{\mathbf{M}} \mathbf{V}_{\mathbf{D C}}\right)^{\mathbf{T}}\left(\mathbf{Y}_{\mathbf{P}}\right)\left(\mathbf{I}_{\mathbf{M}} \mathbf{V}_{\mathbf{D C}}\right)
$$

where $\mathbf{Y}_{\mathbf{P}}$ is the network primitive admittance matrix and $\mathbf{I}_{\mathbf{M}}$ its incidence matrix. The direct voltages at all network nodes are given by $\mathbf{V}_{\mathbf{D C}}$. It is composed by the known direct voltage references-the onshore slack nodes-and the unknown direct voltages from the remaining grid nodes, i.e., the OWFs, hubs and the onshore nodes controlled to fixed power.

In Step 2.2, the MTDC losses are calculated, solving the load flow inside the MTDC network:

$$
\mathrm{V}_{\mathrm{DC}} \cdot \mathrm{Y} \cdot \mathrm{V}_{\mathrm{DC}}^{\mathrm{T}}-\mathrm{P}_{\mathrm{DC}}=\mathbf{0}
$$


where $\mathbf{Y}$ is the network admittance matrix and $\mathbf{P}_{\mathbf{D C}}$ is the active power in the MTDC network nodes.

Step 2.4-Constraints

Although the non-linear equation always returns a load flow solution, extra constraints were implemented in the algorithm to assure the load flows are feasible. The constraints handling was performed through a penalty technique [45]. An augmented fitness, which is the sum of the fitness value (Step 2.3) and the penalty term (Step 2.4), is attributed to each chromosome in Step 2.5. Figure 9 displays the constraints implemented in the GA.

Figure 9. Constraints incorporated in the genetic algorithm.

\begin{tabular}{|c|c|c|}
\hline $\begin{array}{c}\text { VSC stations power } \\
\text { ratings }\end{array}$ & $\begin{array}{l}\text { DC voltage } \\
\text { boundaries }\end{array}$ & $\begin{array}{c}\mathrm{N}-1 \\
\text { redundancy }\end{array}$ \\
\hline \multicolumn{3}{|c|}{ Genetic Algorithm } \\
\hline $\begin{array}{l}\text { OWFs power } \\
\text { production }\end{array}$ & $\begin{array}{l}\text { DC cables } \\
\text { capability }\end{array}$ & Load flow \\
\hline
\end{tabular}

The applied constraints guarantee there are no overloaded dc cables, the dc voltages of all MTDC nodes respect the boundaries (see Table 3 ) and the load flow solutions are $N-1$ secure, i.e., the produced wind power can still be exported, complying with network and TSO constraints, even if an outage occurs in any VSC terminal.

Step 3-Termination Criterion

The algorithm will end whenever the termination criterion is met. The end is triggered whenever the best solution in the population presents a maximum constraint violation lower than $10^{-5}$, as defined in Table 3. When the genetic algorithm finishes solving the OPF problem, it outputs the direct voltage references for the onshore VSC terminals.

Step 4-Selection

After determining the population augmented fitness, the GA continues by selecting solutions from the population (Step 4). It uses an elitist approach to make sure the best solutions in the population will be carried onto the next generation. A 4-th tournament selection is used to populate the mating pool [46].

Step 5-Genetic Operators

To create new solutions after selection, the genetic operators-mutation and crossover-are applied to the mating pool individuals. A point mutation and a heuristic crossover are used [47]. After a new population is created (Step 6), it is evaluated again with regard to the fitness function (Step 2). In Table 3 the parameters used in the genetic algorithm are shown. 


\subsection{Information Flow}

Figure 10 shows how the system is interconnected. Firstly, the information about the OWFs generation is given to the GA, which will obtain optimal power flows according to the constraints. Then, according to the distributed voltage control method, the dc system voltage references are transmitted to the onshore VSC stations for optimal power flow inside the MTDC grid.

It is important to point out that the GA is provided with the OWFs averaged power production over a 5-seconds period. In this way, it is expected that the actual and the desired load flows will somehow differ. However, since 3 OWFs are connected to the MTDC network, it is anticipated that the variability in the total power production will be smoothed out, due to the effect of integrating the wind energy production over a large area.

Note that in the distributed voltage control method, even when receiving a pre-established amount of power, an onshore VSC station will always be operating as a direct voltage regulating node [27]. However, its voltage reference will be determined by the genetic algorithm after solving the optimal MTDC network load flow.

Figure 10. How information flows in the distributed voltage control method.

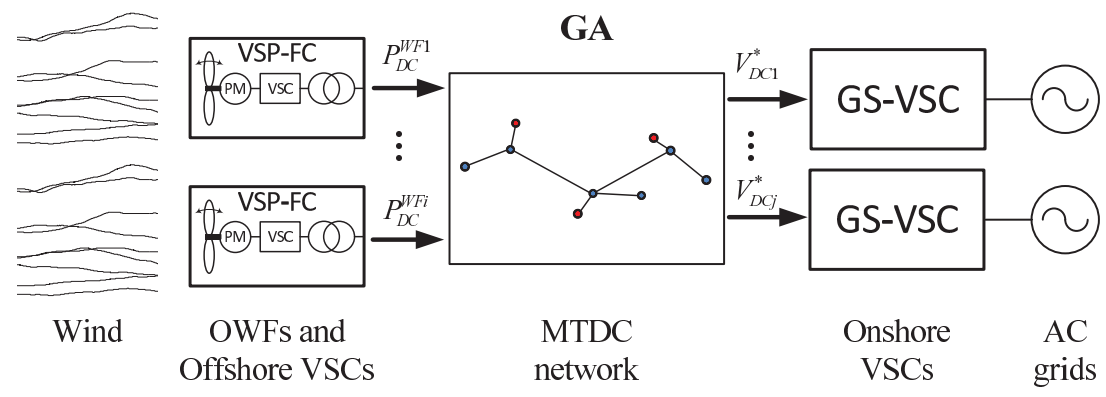

\subsection{Telecommunication Needs for the DVC Method}

For the communication needs, the most important issue to consider is which technology will be employed to transmit the necessary data. Once the technology is chosen, the required transmission time can be straightforwardly obtained. Table 4 shows the advantages and disadvantages for three different telecommunication technologies.

Table 4. Comparison of telecommunication technologies for the DVC strategy.

\begin{tabular}{|c|c|c|}
\hline Technology & Pros & Cons \\
\hline Microwave & $\begin{array}{l}\text { The infrastructure implementation cost is } \\
\text { low since there is no need to install } \\
\text { physical means. }\end{array}$ & $\begin{array}{l}\text { Transmission repeaters might be } \\
\text { necessary, leading to the necessity } \\
\text { for offshore platforms. }\end{array}$ \\
\hline Satellite & $\begin{array}{l}\text { Low implementation cost as all the needed } \\
\text { infrastructure basically already exists. }\end{array}$ & $\begin{array}{l}\text { Low data transmission speed and } \\
\text { reliability can substantially impact the } \\
\text { control cycle time. }\end{array}$ \\
\hline Fiber Optics & $\begin{array}{l}\text { Data reliability, low transmission time, } \\
\text { mature industry for installation of offshore } \\
\text { optic cables. }\end{array}$ & $\begin{array}{l}\text { The main downside is cost. It can be } \\
\text { overcome if integrated in the offshore } \\
\text { HVDC cables. }\end{array}$ \\
\hline
\end{tabular}




\subsubsection{Control Cycle Time-Information Traffic Time}

In the DVC strategy (Figure 10), the information about the OWF power is sent to the ISO, which will solve the OPF problem. Afterwards, the GS-VSC will set their direct voltage according to the reference points received from the ISO. The total time needed to complete one control cycle can be calculated if the amount of data to be transmitted is known. If the data to be transferred is a $14 \mathrm{MB}$ encrypted MATLAB file, with 60 different AC and DC quantities measured at the offshore VSCs with a sampling of $32 \mathrm{~Hz}$ for $15 \mathrm{~min}$, the total time, $T$, to transmit the file is:

$$
\left\{\begin{array}{l}
T=n * T_{f} \\
T_{f}=t_{\text {frame }}+t_{\text {prop } 1}+t_{\text {proc } 1}+t_{\text {prop } 2}+t_{\text {proc } 2}
\end{array}\right.
$$

where $n$ is the number of frames to be sent, whereas $T_{f}$ is the time needed to send one frame. On the other hand, $t_{\text {prop } 1}$ is the propagation time between the OWF-VSCs and the ISO control centre, $t_{\text {proc } 1}$ is the time for the GA to solve the OPF, $t_{\text {prop } 2}$ is the propagation time between the ISO control centre and GS-VSCs, and $t_{\text {proc } 2}$ represents the time to set the GS-VSC voltage to the received reference.

In Equation (12), $t_{\text {proc } 2}$ can be disregard because the VSC can very quickly track the direct voltage reference. On the other hand, $t_{\text {proc } 1}$ is known as it takes about $5 \mathrm{~min}$ for the GA to solve the OPF problem. Thus, considering $t_{\text {prop } 1}$ equal to $t_{\text {prop } 2}$, Equation (12) can be simplified as:

$$
T_{f}=t_{\text {frame }}+2 * t_{\text {prop }}=\frac{L}{R}+2 \frac{d}{v}
$$

where $L$ is the frame size (bits), $R$ is the transmission rate (bps), $d$ is the transmission distance (m) and $v$ is the propagation speed $(\mathrm{m} / \mathrm{s})$. Due to simplifications, the calculated time to transmit one frame, $T_{f}$, can yield larger values than what could be achieved in practice.

\subsubsection{VSAT Satellite}

Each VSC terminal would be equipped with a very small aperture terminal (VSAT) antenna. Commercial bandwidth values are about $512 \mathrm{kbps}$, whereas the frame size is taken equal to 1492 bytes, in accordance with IEEE Ethernet standard 802.3. Hence, transmitting the $14 \mathrm{MB}$ file is equivalent to transmitting $n=14 \mathrm{MB} / 1492$ bytes $=9840$ frames.

For a geostationary satellite, $d$ is equal to two times $35,786 \mathrm{~km}$ (incoming and outgoing signal), and $v$ is the speed of light. Therefore Equation (13) becomes:

$$
T_{f}=\frac{11936[\mathrm{bits}]}{524288[\mathrm{bps}]}+2 * \frac{2 * 35786 * 10^{3}[\mathrm{~m}]}{3 * 10^{8}[\mathrm{~m} / \mathrm{s}]}=22.766+2 * 238.57[\mathrm{~ms}] \approx 500[\mathrm{~ms}]
$$

Substituting the obtained value of $T_{f}$ into Equation (12), the total control cycle time becomes $5220 \mathrm{~s}$, or $87 \mathrm{~min}$, which is too high and even higher than the usual 1 hour dispatch cycle of AC networks. The propagation delay is what mostly determines the total control cycle time. Due to the large distances involved, even if a higher satellite bandwidth was available, the $240 \mathrm{~ms}$ propagation time is the most limiting factor. 


\subsubsection{Fiber Optics}

Offshore-installed VSC transmission stations will probably have fiber optics integrated into the submarine HVDC cables. With fiber optics, the propagation speed, $v$, can be considered to be about $0.67 \mathrm{c}$; whereas the transmission rate can be considered $1 \mathrm{Gbps}$ for a direct connection. For an ISO control centre based in Amsterdam, the biggest involved distance is about $350 \mathrm{~km}$ to the UK onshore node. If a bandwidth of $10 \mathrm{Mbps}$ is available, the total control cycle time would be $345.47 \mathrm{~s}$, or approximately 6 min. However, it is expected that the capital costs of the fiber optics solution would be higher than for satellite. If the data could be compressed to about $25 \%$ of its initial size-since not all data from the VSC terminal needs to be transmitted - the control cycle time using VSAT satellites would be around 25 min, making it a viable option. In contrast, the total control cycle time for the fiber optics solution would not change as much, since the computational time of the GA is the main restricting factor.

\section{Case Studies}

To examine the behavior and capability of the distributed voltage control method in reliably and safely operating the dc network, four different case studies have been selected. Their aim is to show how the DVC method performs when facing some of the most common situations when controlling a MTDC grid for integration of OWFs, i.e., start-up procedures; normal operation; operation under wind curtailment; and operation under a contingency in one ac network node. Table 5 contains the detailed description of all examined case studies and their sub-cases.

Table 5. Description of the analyzed case studies.

\begin{tabular}{|c|c|c|}
\hline \multicolumn{2}{|c|}{ Case Sutdy } & \multirow{2}{*}{$\begin{array}{l}\text { Description } \\
\text { During start-up, the DC system voltage is charged from zero to the rated } \\
\text { value by the GS-VSC terminals. }\end{array}$} \\
\hline $\begin{array}{l}\text { 1. Start-up } \\
\text { Procedures }\end{array}$ & $\begin{array}{l}\text { 1a. MTDC } \\
\text { Start-up }\end{array}$ & \\
\hline \multirow{3}{*}{$\begin{array}{l}\text { 2. Normal } \\
\text { Operation }\end{array}$} & 2a. Priority & $\begin{array}{l}\text { Priority is given to the country where the wind energy is being } \\
\text { produced, i.e., all the power goes to the rightful country; while there } \\
\text { is no energy trade. }\end{array}$ \\
\hline & $\begin{array}{l}\text { 2b. Proportional } \\
\text { Sharing }\end{array}$ & $\begin{array}{l}\text { The sum of all the energy being produced by the OWFs is equally } \\
\text { divided amongst all the countries through energy trade via the } \\
\text { MTDC network. }\end{array}$ \\
\hline & $\begin{array}{l}\text { 2c. Power flow } \\
\text { Reversal }\end{array}$ & $\begin{array}{l}\text { The power flow of the German node is reversed. At first the power is } \\
\text { flowing from the MTDC network into Germany. }\end{array}$ \\
\hline $\begin{array}{l}\text { 3. Wind } \\
\text { Curtailment }\end{array}$ & $\begin{array}{l}\text { 3a. Low-wind } \\
\text { Scenario } \\
\text { 3b. High-wind } \\
\text { Scenario }\end{array}$ & $\begin{array}{l}\text { The MTDC system behavior is analyzed during wind curtailment in a } \\
\text { scenario where the wind energy generation is low. } \\
\text { The MTDC system behavior is analyzed during wind curtailment } \\
\text { in a scenario where the wind energy generation is high. }\end{array}$ \\
\hline \multirow{2}{*}{$\begin{array}{l}\text { 4. AC } \\
\text { Contingency }\end{array}$} & $\begin{array}{l}\text { 4a. Low-wind } \\
\text { Scenario }\end{array}$ & $\begin{array}{l}\text { The system behavior is analyzed during an ac fault at the UK node in a } \\
\text { scenario with low wind energy generation. In this case study the MTDC } \\
\text { network is } N-1 \text { secure. }\end{array}$ \\
\hline & $\begin{array}{l}\text { 4b. High-wind } \\
\text { Scenario }\end{array}$ & $\begin{array}{l}\text { The system behavior is analyzed during an ac fault at the UK node } \\
\text { with high wind generation. In this the MTDC network may not be } \\
N-1 \text { secure. }\end{array}$ \\
\hline
\end{tabular}




\section{Results}

The models presented in Section 2 were implemented in MATLAB/Simulink ${ }^{\circledR}$. The dynamic simulations were performed according to the case studies as described in Table 5. All case studies are simulated for a total time of $150 \mathrm{~s}$. The dynamic simulations are performed in 3 basic steps:

1. The offshore wind farm power series is generated according to Section 2.2 (see Figure 3);

2. An optimal power flow is solved via the genetic algorithm. For simulation purposes, a $5 \mathrm{~s}$ control cycle time based on the OWF average power has been employed (see Sections 3.2-3.4);

3. The MTDC is simulated with the DVC based on the GA-generated direct voltage references.

\subsection{Start-up Procedures (Case Study 1)}

During the MTDC network start-up procedure, the system direct voltage is brought to 1 pu, i.e., $\pm 320 \mathrm{kV}$, by the grid-side voltage-source converters. Figure 11 shows the simulation results for case study 1 . The upper graph shows the active power being injected (positive power) or absorbed (negative power) in the MTDC network by each VSC terminal, whereas the lower graph shows the MTDC voltage at each node.

The first node to unblock its GS-VSC is the UK one, at simulation time $t=0.1 \mathrm{~s}$. The direct voltage controller very rapidly injects about 0.5 pu of power into the MTDC network, bringing the system voltage from zero to $1 \mathrm{pu}$ in about $300 \mathrm{~ms}$. The system voltage does not start from zero but from $0.1 \mathrm{pu}$ (see Figure 11). This is to avoid division by zero, since, according to Equation (4), the current flowing into the dc network is calculated as the active power divided by the dc system voltage.

Figure 11. Results from Case Study 1: MTDC Start-up.
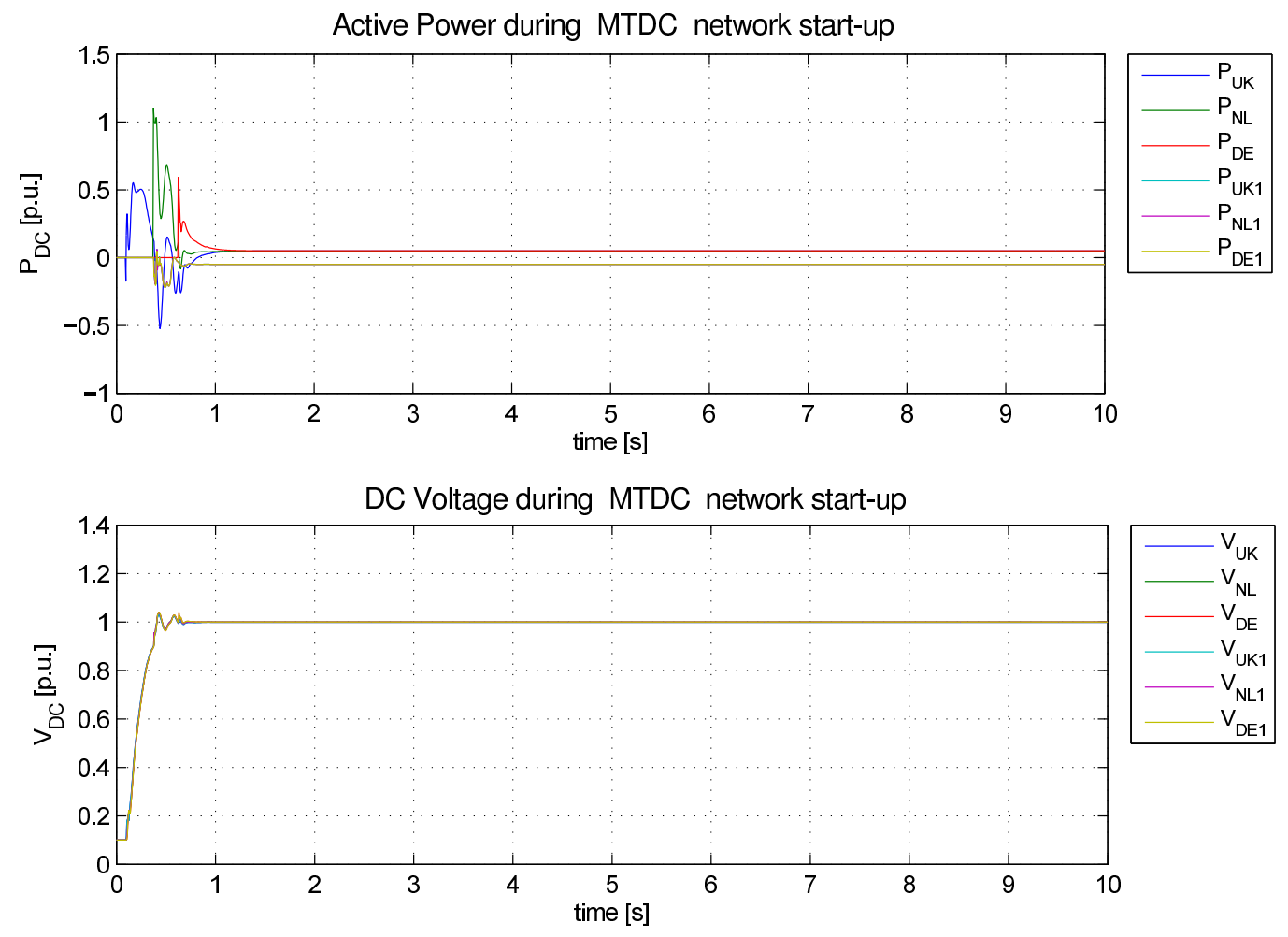
Then, $300 \mathrm{~ms}$ after the UK GS-VSC was unblocked, all other nodes, with exception of the German GS-VSC, are unblocked. The OWFs absorb some power for their own start-up, which makes the transient for the Dutch onshore node somewhat larger than the one for the UK GS-VSC. Finally, the German GS-VSC is unblocked at $t=0.6 \mathrm{~s}$, and the MTDC network undergoes a fast transient, which only creates minor oscillations in the dc system voltage.

The results of case study 1 demonstrate that the complete start-up procedure of the MTDC network can be done very quickly, in less than a second. In reality, such a kick-start might not be needed under normal operation. However, since VSCs do not have the means to block dc faults, and the development of high-power high-current dc short-circuit breakers is yet incipient, being able to promptly black-start the MTDC network might be useful in helping to clear dc faults.

\subsection{Normal Operation (Case Study 2)}

In this case study, the British, Dutch and German OWFs are producing wind energy with an average value of about $0.5 \mathrm{pu}, 0.8 \mathrm{pu}$ and $0.4 \mathrm{pu}$, respectively. Figure 12 shows the simulation results for case study 2. On the left-hand side the OWF-VSC and GS-VSC active power is displayed, while on the right-hand side the dc-side voltage is given.

Instead of sending all the OWF power to the owner state (case study $2 \mathrm{a}$ ), it is possible to share the produced energy via the MTDC grid. In case study $2 b$, the UK, Netherlands and Germany share equally all the power being generated at the OWFs. In this case, the total production is $1.8 \mathrm{pu}$ and each country receives a little less than $0.6 \mathrm{pu}$, which is due to the MTDC grid transmission losses of $0.85 \mathrm{pu}$ on average. In case study 2c, the power flow in the MTDC network is arbitrarily set by the ISO. During the first 20 seconds, the power in the MTDC network is exactly as in case study $2 \mathrm{a}$, where priority is given to the producing country.

Figure 12. Results from Case Study 2: Normal Operation.
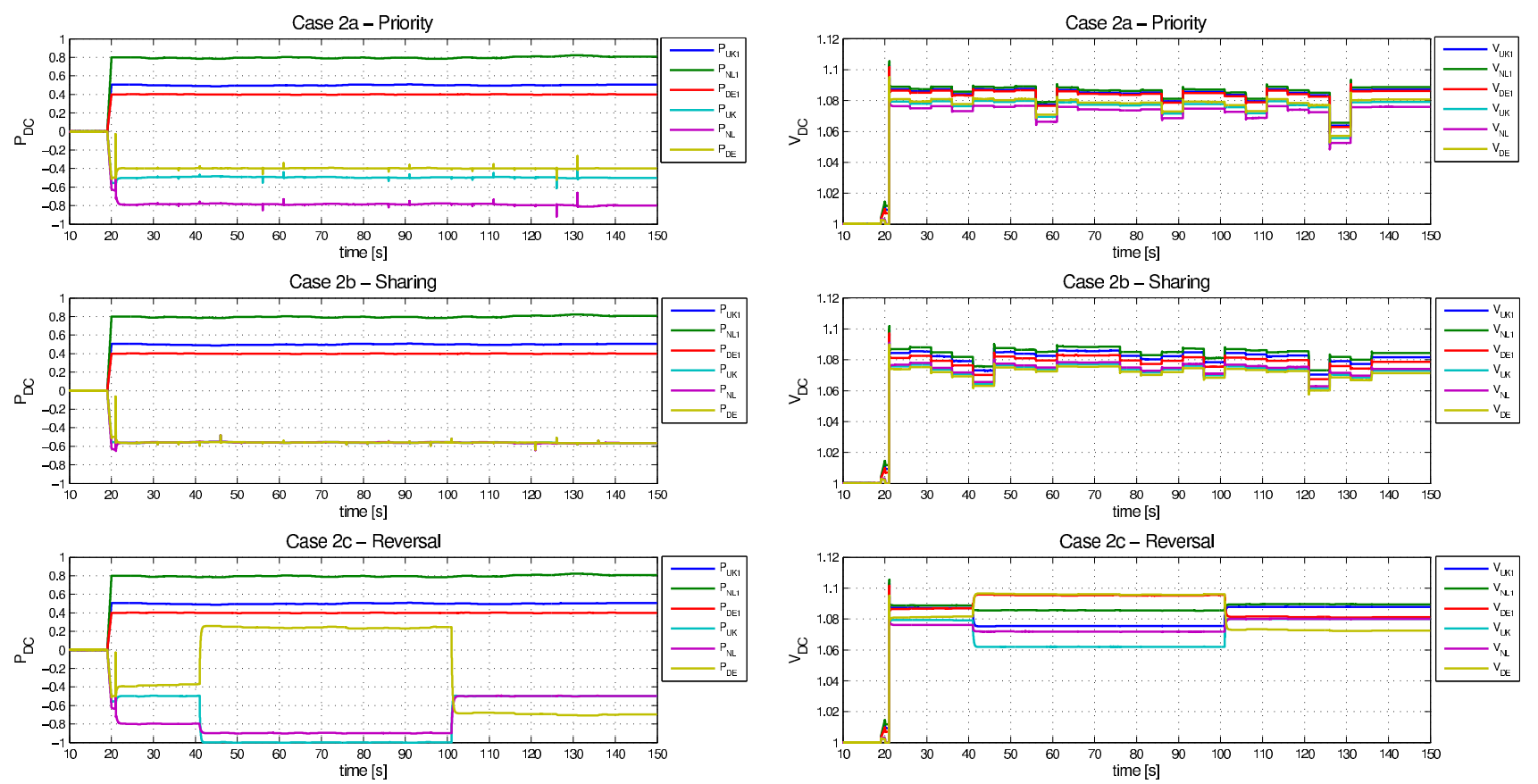
From simulation time $20 \leq t \leq 80 \mathrm{~s}$, the UK onshore node starts receiving $1 \mathrm{pu}$ from the MTDC network, whereas the Dutch node receives $0.9 \mathrm{pu}$. Since the power in the MTDC network has to be balanced at all times, the power flow in the German node is reversed. During that period, the German onshore node will be injecting - i.e., selling-about $0.20 \mathrm{pu}$ of power to the MTDC grid.

It is worth noting the onshore nodes are effectively controlling their dc-side voltage and not directly the load-flow, as the DVC method dictates. Nevertheless, Germany is the node that is providing the extra power to balance the MTDC network losses. This is achieved in the OPF optimization by setting Germany as the solely slack node. The purpose is to speed up the OPF solution with the genetic algorithm. Towards the end of the simulation, the power from the German node is again reversed as the power to the British and Dutch node is set by the ISO as being equal to $0.5 \mathrm{pu}$.

\subsection{Wind Curtailment (Case Study 3)}

The third case study analyzes the distributed voltage controller behavior when the offshore wind farm power has to be curtailed. In the low-wind scenario, the British, Dutch and German OWFs are producing wind energy with an average value of about $0.5 \mathrm{pu}, 0.8 \mathrm{pu}$ and $0.4 \mathrm{pu}$, respectively, thus the total production of the OWFs is $1.8 \mathrm{pu}$.

In case $3 \mathrm{a}$, before the curtailment starts at $t=40 \mathrm{~s}$, the ISO is setting the DVC strategy to priority control as in case $2 \mathrm{a}$; hence, until that point in time, the results of both cases are identical. Afterwards, from $40 \leq t \leq 60 \mathrm{~s}$, the Dutch and German OWFs are ordered to curtail their power outputs to 0.4 and $0.3 \mathrm{pu}$, respectively. The OWFs total power production after curtailment is $1.2 \mathrm{pu}$, so the power at the GS-VSC also needs to change to accommodate the curtailment. Nevertheless, even during the curtailment, the DVC strategy can control the power flow inside the MTDC network.

In fact, when the curtailment starts, the ISO changes the direct voltage set-points of the British and Dutch nodes in order to make each node receive respectively $1.0 \mathrm{pu}$ and $0.4 \mathrm{pu}$ of power, while the German node produces the additional 0.2 pu to compensate for some of the power that was curtailed.

The results of case study 3 a show (see Figure 13) that the changes in power are both fast and smooth, while the MTDC system voltage is controlled within the limit of $\pm 10 \%$ the rated value. Meanwhile, the DVC strategy still guarantees that the MTDC network is operating with minimum losses for the chosen load-flow operating point whilst the MTDC system is N-1 secure. Finally, at $t=100 \mathrm{~s}$, the OWF production is ramped back and the MTDC network is brought back to the initial operating point.

In the high-wind-scenario case study (case study 3b), the total production at the OWFs is $2.4 \mathrm{pu}$. In the beginning of the simulation, a sharing control strategy is being used (as in case study $2 b$ ) and each onshore node receives approximately the same amount of power (circa $0.8 \mathrm{pu}$ ). The ISO then commands all OWFs to curtail their power to 0.4 pu from $40 \leq t \leq 60 \mathrm{~s}$. Once more, the total power production after curtailment is $1.2 \mathrm{pu}$. Therefore, the ISO can send new voltage set-points to the GS-VSCs so the British and Dutch nodes receive $1.0 \mathrm{pu}$ and $0.4 \mathrm{pu}$ of power, respectively, while the German node produces $0.2 \mathrm{pu}$. This load-flow operating point can of course be arbitrarily chosen by the ISO, provided it respects the MTDC power balance and the GS-VSC power ratings. At $t=100 \mathrm{~s}$, the OWF production is restored to the initial values and the sharing control strategy is re-established. 
Figure 13. Results from Case Study 3: Wind Curtailment.
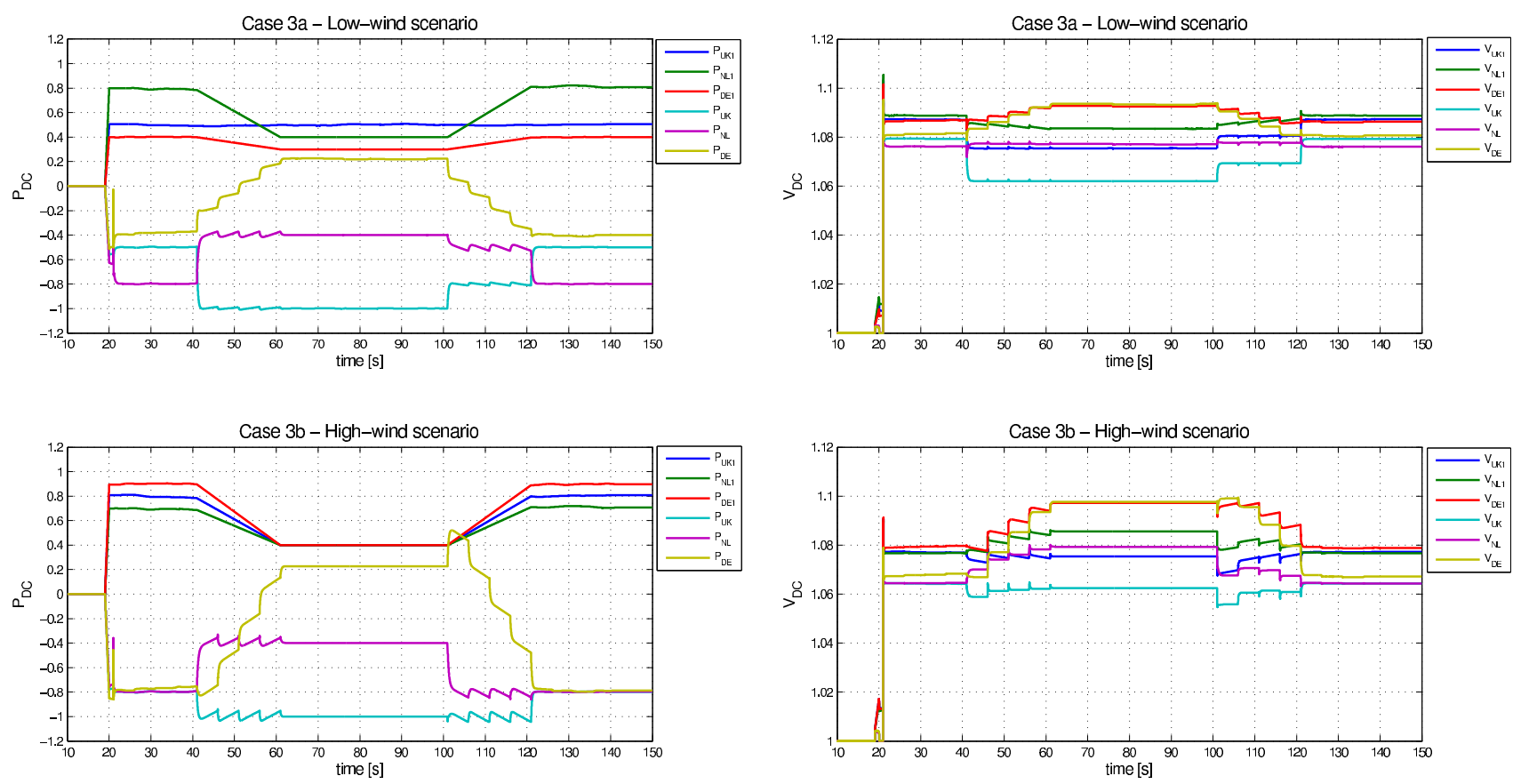

\subsection{AC Contingency (Case Study 4)}

The goal of the last case study is to analyze the DVC strategy behavior during a fault in one ac network node. The fault takes place in the ac-side of the UK onshore node. The case study shows the response of the MTDC system to the fault during two different wind scenarios: low-wind scenario (total generation is $1.8 \mathrm{pu}$ ) and high-wind scenario (total generation is $2.4 \mathrm{pu}$ ). The fault lasts $40 \mathrm{~s}$, starting from $t=40 \mathrm{~s}$. The longer fault is applied to better visualize the transients involved when one MTDC network node is lost. Figure 14 shows the active power and direct voltage for both cases. It also shows that the DVC strategy can successfully ride through the fault in both cases, although the dynamic response varies according to the wind scenario.

In the low-wind scenario, the sum of the remaining GS-VSC rated power is lower than the power being produced offshore. Therefore, the MTDC network is $N-1$ secure and there is no need to change the OWF power output during the fault. In case 4a, as seen in Figure 14, when the fault happens in the UK node, the power at the Dutch and German onshore node rapidly changes to re-establish power balance in the dc grid. This occurs because all the GS-VSC are effectively controlling the dc system voltage, which is one of the DVC method's greatest advantages. During this very fast transient, the MTDC voltage reaches a peak of $1.11 \mathrm{pu}$, but is quickly restored back to values within the operating limit. When the fault is cleared, at $t=80 \mathrm{~s}$, the MTDC system voltage undergoes another transient, this time only a direct voltage dip to about $1.04 \mathrm{pu}$, which is much less of concern than the voltage spike when the fault occurs. Finally, at $t=100$, the priority control strategy is reinstalled by the DVC method and the MTDC network goes back to its initial operating point. 
Figure 14. Results from Case Study 4: AC fault in the UK node.
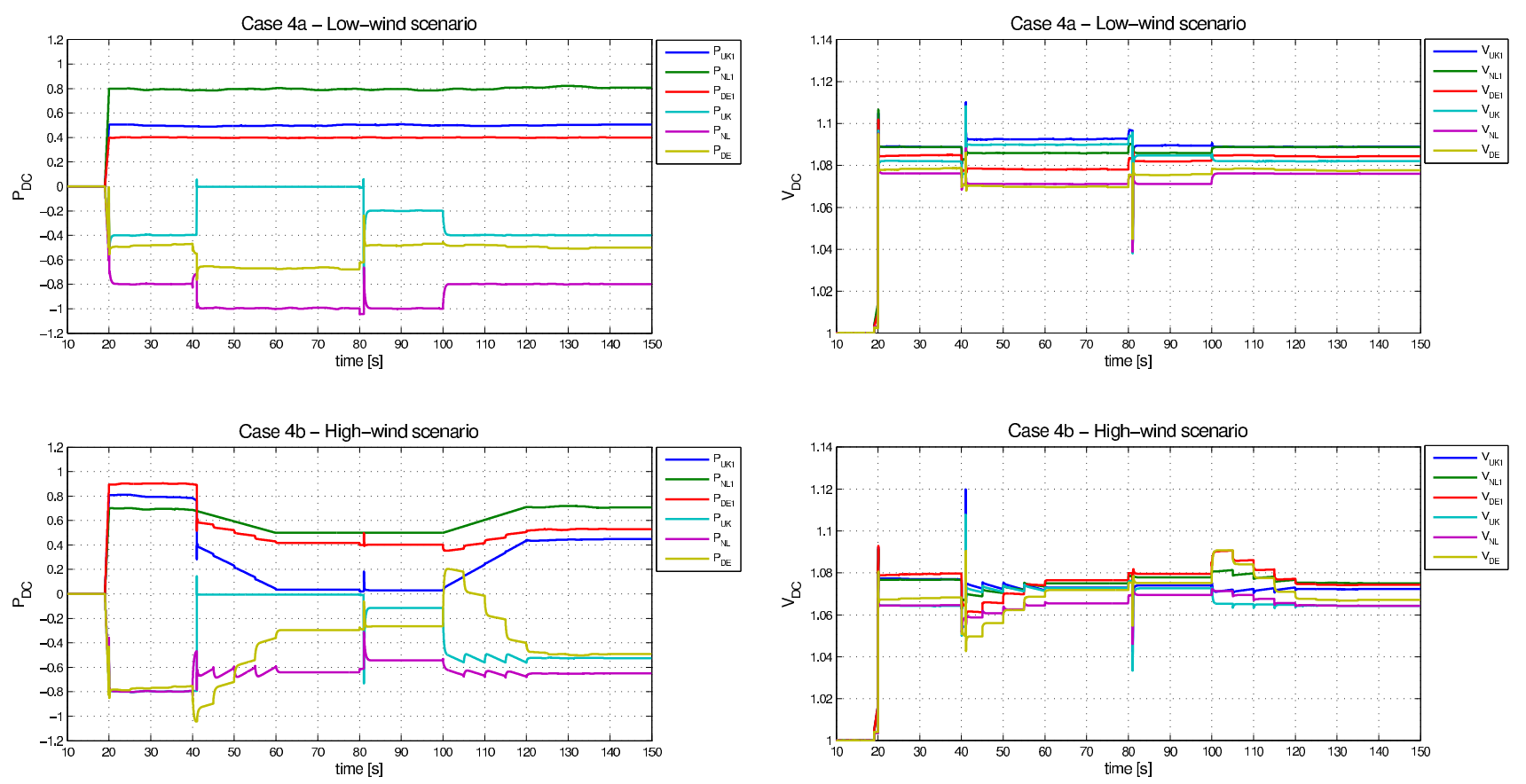

Contrarily, in the high-wind scenario, the MTDC network is not $N-1$ secure since the total power being produced, $2.4 \mathrm{pu}$, is higher than the remaining onshore VSC combined ratings, which is $2 \mathrm{pu}$. In that case, the DVC strategy cannot alone keep the MTDC network voltage secure by increasing active power absorption at the onshore GS-VSC terminals. In case 4b (see Figure 14), when the fault happens, dc choppers are activated on the German and UK OWFs once the direct voltage exceeds $1.10 \mathrm{pu}$. Then, after the fault, the OWFs start to curtail their power outputs, which was not necessary before. Additionally, since in high-wind case more power was being produced prior to the fault than in comparison with the low-wind case, the MTDC voltage transient peak is higher, with a maximum of 1.12 pu being reached at the UK offshore node. Finally, when the fault is cleared, at $t=80 \mathrm{~s}$, the offshore wind farm power output is kept constant for $20 \mathrm{~s}$ and then ramped up, starting from $t=100 \mathrm{~s}$, to a new operating point, this time $\mathrm{N}-1$ secure. A new load-flow scenario is established from $t=120 \mathrm{~s}$ onwards.

\subsection{Transmission Losses and Trade}

The transmission losses and the power being traded in the MTDC network are shown in Figure 15 for all the analyzed case studies.

The transmission losses are given as a function of the total generated power at the offshore wind farms and the power trade is given in a per unit basis. They are calculated as:

$$
\begin{aligned}
& P_{\text {loss }}=\sum_{j=1}^{6} R_{j} * I_{D C_{j}}^{2} / \sum_{j=1}^{3} P_{D C_{j}}^{O W F} \\
& P_{\text {trade }}=1 / 2 \sum_{j=1}^{3}\left(\left|P_{V S C_{j}}-P_{O W F_{j}}\right|\right)
\end{aligned}
$$


The MTDC system losses are optimized by the GA, which has the transmission losses as objective function. Figure 15 shows that the MTDC transmission losses vary between $1 \%$ and $3 \%$ of the total generated power. The total MTDC system losses are higher since the VSC losses should also be taken into account.

It is interesting to note that, as one would expect, the transmission losses and the power traded in the MTDC network have basically the same trend. This is due to the fact that trade, as calculated by Equation (15), happens through lines 3 and 6, i.e., the hub lines, which are the longest lines in the MTDC network.

Figure 15. Transmission losses in the MTDC system in percentage of the total generated power and power traded in the MTDC system in per unit of the system power base.
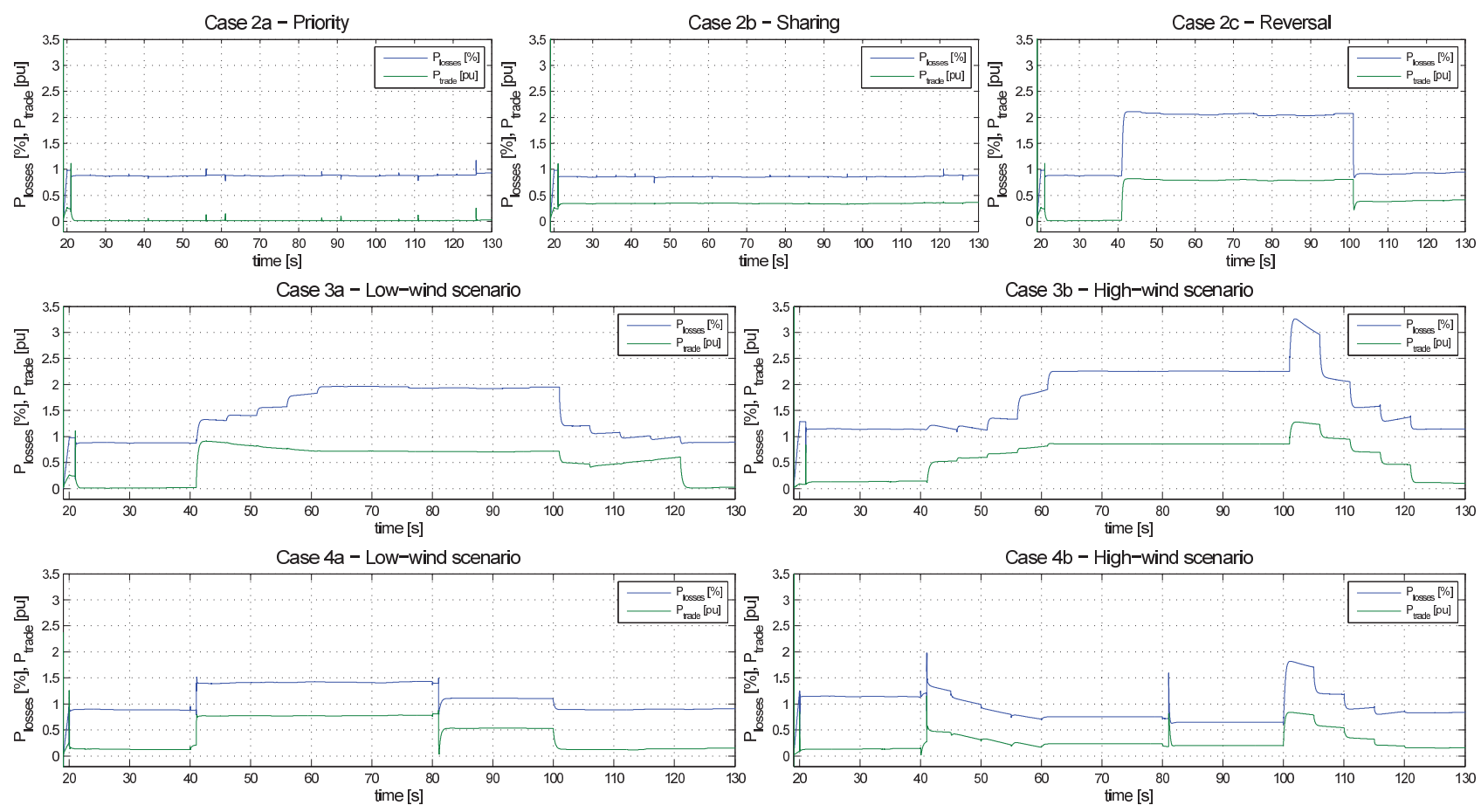

\section{Conclusions}

The increasing interest in integrating renewable electricity from remotely located energy sources, such as offshore wind power, is promoting the development of high-voltage multi-terminal DC networks, which offer several advantages when compared with standard high-voltage AC networks. In that matter, the VSC-HVDC technology stands out as the most promising solution. However, several regulatory as well as technical challenges must be addressed before such MTDC systems can be erected.

The paper has described the dynamic models of the main components in an MTDC network. A novel control method, the distributed voltage control (DVC) strategy, has been presented to control the DC power flow. The DVC strategy was analyzed in combination with a genetic algorithm that minimizes the MTDC system losses. A total of eight different case studies have been conducted, via dynamic simulations, in MATLAB Simulink. The simulation results demonstrated that the proposed control strategy is capable of reliably and safely controlling the DC power flow. Furthermore, it was 
shown that the DVC strategy does not rely on fast communications and can handle the power flow in complex DC networks.

Future work involves building a small-scale version of the represented MTDC network in a laboratory, testing the distributed voltage controllers in a real-time environment, and assessing the effect of direct voltage measurement errors on the dc load flow obtained with the DVC strategy.

\section{Acknowledgments}

This research is financially supported by Agentschap NL, an agency of the Dutch Ministry of Economic Affairs, Agriculture and Innovation, under the project North Sea Transnational Grid (NSTG). NSTG is a joint project of Delft University of Technology and the Energy Research Centre of The Netherlands.

\section{References}

1. MacKay, D. Sustainable Energy-Without the Hot Air, 3.5.2 ed.; UIT Cambridge Ltd.: Cambridge, UK, 2008; pp. 1-383.

2. Bresesti, P.; Kling, W.L.; Hendriks, R.L.; Vailati, R. HVDC connection of offshore wind farms to the transmission system. IEEE Trans. Energy Convers. 2007, 22, 37-43.

3. Pierik, J.; Axelsson, U.; Eriksson, E.; Salomonsson, D.; Bauer, P.; Czech, B. A wind farm electrical systems evaluation with EeFarm-II. Energies 2010, 3, 619-633.

4. Vrana, T.; Torres-Olguin, R.; Liu, B.; Haileselassie, T. The North Sea Super Grid-a technical perspective. In Proceedings of 9th IET International Conference on AC and DC Power Transmission; London, UK, 19-21 October 2010; pp. 1-5.

5. Van der Meer, A.; Teixeira Pinto, R.; Gibescu, M.; Bauer, P.; Pierik, J.; Nieuwenhout, F.; Hendriks, R.; Kling, W.; van Kuik, G. Offshore Transnational Grids in Europe: The North Sea Transnational Grid Research Project in Relation to Other Research Initiatives. In Proceedings of 9th International Workshop on Large-Scale Integration of Wind Power; Quebec, Canada, 18-19 October 2010; pp. 1-8.

6. Bang, D.J. Design of Transverse Flux Permanent Magnet Machines for Large Direct-Drive Wind Turbines. Ph.D. Thesis, Delft University of Technology, Delft, The Netherland, 2010.

7. London Array-The World's Largest Offshore Wind Farm. Available online: http://www.londonarray.com/2012/10/29/worlds-largest-offshore-wind-farm-generates-firstpower/ (accessed on 21 December 2012).

8. Decker, J.D.; Tambke, J.; Volker, J.; Michalowska-Knap, K. An offshore transmission grid for wind power integration: The European techno-economic study OffshoreGrid. In Proccedings of 2010 IEEE Power and Energy Society General Meeting, Minneapolis, MN, USA, 25-29 June 2010.

9. Kling, W.; Hendriks, R.; den Boon, J.H. Advanced transmission solutions for offshore wind farms. in Proceedings of IEEE Power and Energy Society General Meeting, Pittsburgh, PA, USA, 20-24 July 2008.

10. Roggenkamp, M.; Hendriks, R. Market and regulatory aspects of trans-national offshore electricity networks for wind power interconnection. Wind Energy 2010, 13, 483-491. 
11. Garces, A.; Molinas, M. A study of efficiency in a reduced matrix converter for offshore wind farms. IIEEE Trans. Ind. Electron. 2012, 59, 184-193.

12. Blasco-Gimenez, R. Diode-Based HVdc link for the connection of large offshore wind farms. IEEE Trans. Energy Convers. 2011, 26, 615-626.

13. Ludois, D.; Venkataramanan, G. An examination of AC/HVDC power circuits for interconnecting bulk wind generation with the electric grid. Energies 2010, 3, 1263-1289.

14. Shao, S.J.; Agelidis, V.G. Review of DC system technologies for large scale integration of wind energy systems with electricity grids. Energies 2010, 3, 1303-1319.

15. Denniston, N.; Massoud, A.M.; Ahmed, S.; Enjeti, P.N. Multiple-module high-gain high-voltage DC-DC transformers for offshore wind energy systems. IEEE Trans. Ind. Electron. 2011, 58, 1877-1886.

16. Lopez, A.; Diez, R. Analysis and comparison of three topologies of the ladder multilevel DC/DC converter. IEEE Trans. Power Electron. 2012, 27, 3119-3127.

17. De Kerf, K.; Srivastava, K.; Reza, M.; Bekaert, D.; Cole, S.; van Hertem, D.; Belmans, R. Waveletbased protection strategy for DC faults in multi-terminal VSC HVDC systems. IET Gener. Transm. Distrib. 2011, 5, 496-503.

18. Tang, L.; Ooi, B. Protection of VSC-multi-terminal HVDC against DC faults. In Proceedings of IEEE 33rd Annual Power Electronics Specialists Conference (PESC'02), Cairns, Queensland, Australia, 23-27 June 2002; IEEE: New York, NY, USA, 2002; Volume 2, pp. 719-724.

19. Candelaria, J.; Park, J. VSC-HVDC System Protection: A Review of Current Methods. In Proceedings of 2011 IEEE/PES, Power Systems Conference and Exposition (PSCE), Phoenix, AZ, USA, 20-23 March 2011; IEEE: New York, NY, USA, 2011; pp. 1-7.

20. Glasdam, J.; Bak, C.L.; Hjerrild, J. Transient studies in large offshore wind farms employing detailed circuit breaker representation. Energies 2012, 5, 2214-2231.

21. Mura, F. Stability analysis of high-power dc grids. IEEE Trans. Ind. Appl. 2010, 46, 584-592.

22. Wang, L.; Hsiung, C. Dynamic stability improvement of an integrated grid-connected offshore wind farm and marine-current farm using a STATCOM. IEEE Trans. Power Syst. 2011, 26, 690-698.

23. Gomis-Bellmunt, O. Control of a wind farm based on synchronous generators with a central HVDC-VSC converter. IEEE Trans. Power Syst. 2011, 26, 1632-1640.

24. $\mathrm{Xu}, \mathrm{L}$; Y Yao, L. DC voltage control and power dispatch of a multi-terminal HVDC system for integrating large offshore wind farms. IET Renew. Power Gener. 2011, 5, 223-233.

25. Prieto-Araujo, E. Methodology for droop control dynamic analysis of multiterminal VSC-HVDC grids for offshore wind farms. IEEE Trans. Power Deliv. 2011, 26, 2476-2485.

26. Barambones, O. Sliding mode control strategy for wind turbine power maximization. Energies 2012, 5, 2310-2330.

27. Teixeira Pinto, R.; Bauer, P.; Rodrigues, S.F.; Wiggelinkhuizen, E.J.; Pierik, J.; Ferreira, B. A novel distributed direct voltage control strategy for grid integration of offshore wind energy systems through MTDC network. IEEE Trans. Ind. Electron. 2012, PP (99), 1-13.

28. Li, P.; Banakar, H.; Keung, P. Macromodel of spatial smoothing in wind farms. IEEE Trans. Energy Convers. 2007, 22, 119-128. 
29. Slootweg, J.; Haan, S.; Polinder, H.; Kling, W.L. Modeling Wind Turbines in Power System Dynamics Simulations. In Proceedings of Power Engineering Society Summer Meeting, Vancouver, Canada, 15-19 July 2001; pp. 22-26.

30. Zhou, Y.; Bauer, P. Operation of grid-connected DFIG under unbalanced grid voltage condition. IEEE Trans. Energy Convers. 2009, 24, 240-246.

31. Wouters, D.; van Engelen, T. Modern Wind Turbine Controller Design. In Proceedings of the Global Wind Power Conference, Paris, France, 2-5 April 2008; pp. 1-7.

32. Aredes, M.; da Cunha De Aquino, A.F.; Portela, C.; Watanabe, E. Going the distance-PowerElectronics-Based Solutions for Long-Range Bulk Power Transmission. IEEE Ind. Electron. Mag. 2011, 5, 36-48.

33. Teixeira Pinto, R.; Rodrigues, S.; Bauer, P.; Pierik, J. Comparison of Direct Voltage Control Methods of Multi-terminal DC (MTDC) Networks Through Modular Dynamic Models. In Proceedings of the 14th European Conference on Power Electronics and Applications (EPE 2011), Birmingham, UK, 30 August-1 September 2011; IEEE-PESC: Birmingham, UK, 2011; pp. 1-10.

34. Teixeira Pinto, R.; Bauer, P. Modular Dynamic Models of Large Offshore Multi-terminal DC (MTDC) Networks. In Proceedings of European Wind Energy Association Conference (EWEC), Brussels, Belgium, 14-17 March 2011; pp. 1-10.

35. Tsili, M.; Papathanassiou, S. A review of grid code technical requirements for wind farms. IET Renew. Power Gener. 2009, 3, 308-332.

36. Erlich, I.; Bachmann, U. Grid Code Requirements Concerning Connection and Operation of Wind Turbines in Germany. In Proceedings of IEEE Power Engineering Society General Meeting, San Francisco, CA, USA, 24-28 June 2005, pp. 2230-2234.

37. Barlow, M.; Theodoridis, M.; Bishop, M.T. The design of wind plant reactive compensation system alternatives to meet grid code requirements. In Proceedings of 2nd IEEE PES International Conference and Exhibition on Innovative Smart Grid Technologies, Manchester, UK, 5-7 December 2011; IEEE: New York, NY, USA, 2011; pp. 1-8.

38. Zhang, L.; Harnefors, L.; Nee, H. Interconnection of two very weak ac systems by VSC-HVDC links using power-synchronization control. IEEE Trans. Power Syst. 2011, 26, 344-355.

39. Xu, L.; Williams, B. Multi-terminal DC transmission systems for connecting large offshore wind farms. In Proceedings of Power and Energy Society General Meeting, Pittsburg, PA, USA, 20-24 July 2008; pp. 1-7.

40. Tokiwa, Y.; Ichikawa, F. Novel control strategies for HVDC system with self-contained converter. Electr. Eng. Jpn. 1993, 113, pp. 1-13.

41. Rodrigues, S.; Pinto, R.T.; Bauer, P.; Wiggelinkhuizen, E.J.; Pierik, J. Optimal Power Flow of VSC-based Multi-Terminal DC Networks using Genetic Algorithm Optimization. In Proceedings of 2012 IEEE Energy Conversion Congress and Exposition (ECCE), Raleigh, NC, USA, 15-20 September 2012; pp. 1-8.

42. Rodrigues, S.; Teixeira Pinto, R.; Bauer, P.; Pierik, J. Optimization of social welfare and transmission losses in offshore MTDC networks through multi-objective genetic algorithm. In Proceedings of 7th International Power Electronics and Motion Control Conference (IPEMC), Harbin, China, 2-5 June 2012; Volume 2, pp. 1287-1294. 
43. Holland, J.H. Adaptation in Natural and Artificial Systems; University of Michigan Press: Ann Arbor, MI, USA, 1975; pp. 1-200.

44. Haupt, R.L.; Werner, D.H. Genetic Algorithms in Electromagnetics; Wiley-IEEE Press: Hoboken, NJ, USA, 2007.

45. Gen, M.; Cheng, R. A survey of penalty techniques in genetic algorithms. In Proceedings of IEEE International Conference on Evolutionary Computation, Nagoya, Japan, 20-22 May 1996; IEEE: New York, NY, USA; Volume 31, pp. 804-809.

46. Maulik, U.; Bandyopadhyay, S.; Mukhopadhyay, A. Multiobjective Genetic Algorithms for Clustering; Springer-Verlag GmbH: Heidelberg, Germany, 2011; p. 83.

47. Adewuya, A.A. New Methods in Genetic Search with Real-Valued Chromosomes. Master's Thesis, Massachusetts Institute of Technology, Cambridge, MA, USA, 1996.

(c) 2013 by the authors; licensee MDPI, Basel, Switzerland. This article is an open access article distributed under the terms and conditions of the Creative Commons Attribution license (http://creativecommons.org/licenses/by/3.0/). 